\title{
Hacia el establecimiento de un Tribunal Penal Internacional permanente y un Código Penal Internacional. Observaciones desde el punto de vista del Derecho Penal Internacional ${ }^{*}$
}

Kai Ambos

\section{Introducción}

La casi total impunidad para los crímenes de guerra y graves violaciones a los derechos humanos, producidos en la antigua Yugoslavia o en países con menor interés público como Colombia o Perú, Togo o Liberia -para mencionar sólo algunos casos- nos llaman a reflexionar sobre el desarrollo futuro de los mecanismos de justicia penal internacional. Los esfuerzos en esa dirección, ${ }^{1}$ que se remontan a los tribunales de guerra de Nuremberg y Tokio, experimentaron un sorpresivo empuje político al finalizar la Guerra Fría con el establecimiento de los tribu-

\footnotetext{
* Estoy muy agradecido a la Srta Virginia Morris de la División de Codificación de las Naciones Unidas y al Prof. Dr. Christian Tomuschat de la Universidad Humboldt de Berlín, al Dr. Simon de la Biblioteca de la ONU en Ginebra y a la Dra. Schlunck del Ministerio de Justicia federal (Bonn) por la información que me proporcionaron para la confección de este trabajo. Asimismo, me encuentro en deuda con Alicia Gil de la Universidad Nacional de Educación a Distancia (NED/España) y con Gustavo A. Bruzzone de la Universidad de Buenos Aires (U.B.A.) por haber traducido al castellano este trabajo originariamente publicado en el European Journal for International Law (EJIL), t.7 (1966), pp. 519 a 544.

1 Los trabajos para el establecimiento de un TPIP comenzaron al final de los $40^{\prime}$ pero, prácticamente, se suspendieron entre 1954 a 1981 (sobre antecedentes y desarrollo ver: J. Deschenes, Towards international criminal justice; Criminal Law Forum (en adelante: CLF), vol 5, No 2-3 (1994), pp. 249-278, 272 y ss.; P. Burns, An international criminal tribunal: the difficult union for principle and politics, CLF, vol. 5, $\mathrm{N}^{\circ} 2-3$ (1994), pp. 341 a 380, 351 y ss.). En el periodo de la post-guerra, particularmente la Association Internationale de Droit Pénal (AIDP) así como los profesores $\mathrm{H}-\mathrm{H}$. Jescheck (Freiburg, presidente honorario de la AIDP), O. Triffterer (Salzburg) y Ch. Bassiouni (Chicago) han continuado trabajando sobre este tema. Bassiouni, por ejemplo, ha propuesto su propio proyecto: Draft Statute International Tribunal, Toulouse (AIDP) 1993.
} 
nales ad-hoc para la antigua Yugoslavia ${ }^{2}$ y Ruanda. ${ }^{3}$ Recientemente también se han realizado esfuerzos de codificación tanto en el plano sustantivo como en el procesal. La Comisión de Derecho Internacional de las Naciones Unidas (en adelante "CDI») elaboró un proyecto de Estatuto para establecer un Tribunal Penal Internacional permanente («TPIP») en 1994 ( (Proyecto de Estatuto de la CDI» ${ }^{4}$ ) y co-

2 En adelante "Estatuto de Yugoslavia». El texto puede ser encontrado en el documento de las Naciones Unidas (UN) S/25704, del 3/5/93, par. 32 y ss. Fue aprobado por la resolución 827 del Consejo de Seguridad de las Naciones Unidas (CS) del 25 de mayo de 1993. Las "Reglas sobre procedimiento y prueba" fueron adoptadas por el Tribunal el $11 \mathrm{de}$ febrero de 1994 (Documentos de las Naciones Unidas (NU-Doc.) IT/32, 14/3/1994; 33 ILM, 1994, pp. 493 y ss) con reformas más recientes del 23/4/96 (IT/73/Rev.8). Respecto de la designación de defensores ver las "directivas para la designación de defensores» (IT/73/ Rev. 2, 30/1/1995). Respecto del Estatuto ver, en particular, K. Oellers-Frahm, "Das Statut des Internationalen Strafgerichtshofs zur Verfolgung von Kriegsverbrechen im ehemaligen Jugoslawien", en : ZaöRV 54/2 (1994), pp. 416 a 445; B. Graefrath, "Jugoslawien und die internationale Strafgerichtsbarkeitı, en: Hankel/Stuby (eds.), Strafgerichte gegen Menschheitsverbrechen: Zum Völkerstrafrecht 50 Jabre nach den Nïrnberger Prozessen, Hamburg 1995, pP. 295 a 324; J. C. O'Brien, "The International Tribunal for Violations of International Humanitarian Law in the former Yugoslavia", 87 EJIL (1993), pp. 639 a 659 y R. Zacklin/D. Shraga, "The International Criminal Tribunal for the Former Yugoslavia», 5 EJIL (1994), pp. 360 a 380. Respecto al primer caso práctico (Tadic y Nikolic) ver L. Vierucci, "The First Steps of the International Criminal for the Forner Yugoslavia». 6 EJIL (1995), pp. 34 a 149; R. Maison, "La décision de la Chambre de première instance $N^{\circ} 1$ du Tribunal pénal international pour l'exYougoslavie dans l'affaire Nikolic», 7 EJIL (1966, pp. 284 a 299; y más adelante nota 2. Acerca de los antecedentes políticos ver: D. Forsythe, "Politics and the International Tribunal for the Former Yugoslavia", CLF vol. 5, No 2-3 (1994), pp. 401 a 422. En cuanto a las "Reglas" ver J. E. Schutte, "Legal and practical implications from the perspective of the host country, relating to the establishment of the International Tribunal for the Former Yugoslavian, CLF vol. 5, No 2-3 (1994), pp. 423 a 450, 431 y ss.; D. Nsereko, "Rules of procedure and evidence of the International Tribunal for the Former Yugoslavia", CLF vol. 5, No 2-3 (1994), PP. 507 a 555. En lo concerniente al Dayton agreement (acuerdo Dayton): 7 EJIL (1996), pp. 147 a 244. Un análisis global se encuentra ahora en Bassiouni/Manikas, The law of the International Criminal Tribunal for the Former Yugoslavia, N.Y. 1996.

3 Resolución del CS 955 (1994), UN-Doc. S/Res/955 (1994), 8 de noviembre de 1994. Las reglas de procedimiento y prueba fueron adoptadas el 29/6/95 (ITR/3/Rev.1), una segunda revisión fue realizada a mediados de 1996.

4 "DRAFT Statute for an International Criminal Court" (Informe de la CDI de los trabajos de la 46a. Sesión, 2/5-22/7/94, Asamblea General de las Naciones Unidas (AG), registros oficiales, 49a. Sesión, suplemento $\mathrm{N}^{\circ} 10$ (A/49/10), par. 42-91, pp. 29 a 161). Respecto del proyecto del "Grupo de Trabajo" ver J. Crawford, "The ILC's Draft Statute for an international Criminal Tribunal", 88 AJIL (1994), pp. 140 a 152; lo mismo en, "The ILC adopts a Statute for an Interntional Criminal Court", 89 AJIL (1995), pp. 404 a 416. Adicionalmente, varios otros proyectos también han influido a la CDI (ver Bassiouni, supra nota 1, pp. 3 y ss., 28 y ss., donde se enumeran, en total, 11 proyectos oficiales y 10 no oficiales). 
menzó a reelaborar su «Proyecto de Código de Crímenes contra la Paz y la Seguridad de la Humanidad", aprobándose una versión preliminar en 1991 (en adelante Proyecto de Código de $1991^{5}$ ) y la final en 1996 (Proyecto de Código de 19966).

De acuerdo con el Proyecto de Estatuto de la CDI la Asamblea de las Naciones Unidas (AG) en la 49a Sesión de 1994 decidió establecer una "Comisión ad-hoc para el establecimiento de un TPIP», la que se desarrolló en dos sesiones en 1994. En la 50a Sesión de 1995 la AG decidió, sobre la base del informe ${ }^{7}$ de la Comisión ad hoc, designar un "Comité Preparatorio para el establecimiento de un TPIP» ("Com. Prep») que deberá preparar el texto de una convención para ser analizado por los representantes plenipotenciarios. En su primera sesión, llevada a cabo entre marzo y abril de 1996, la Comisión Preparatoria consideró cuestiones materiales, de procedimiento y administrativas; ${ }^{8}$ en su segunda sesión (agosto de 1996) tomó en consideración el Proyecto de Código de 1996 y se ocupó de un mayor número de cuestiones procesales y organizativas para concretar el establecimiento de un TPIP.? En el año en curso (1997) se encuentran previstas tres sesiones para seguir adelante con la discusión.

Paralelamente, y de forma independiente, un comité de expertos se reunió en Siracusa (Italia) en junio de 1995 para discutir un proyecto alternativo ("Proyecto alternativo") al Proyecto de la CDI. ${ }^{10}$ Este Pro-

5 "Draft Code of Crimes against the Peace and Security of Mankind", (Informe de la CDI sobre el trabajo de la 45a. Sesión, 29/4 al 19/7/91, AG, registros oficiales, 46a. Sesión, Suplemento $\mathrm{N}^{\circ} 10, \mathrm{~A} / 46 / 10$, pp. 238 y ss.). Ver Bassiouni (Ed.), Commentaries on the International Law Commission's 1991 Draft Code of Crimes against the Peace and Security of Mankind, Toulouse (AIDP) 1993; C. Tomuschat, "Die Arbeit der ILC im Bereich des materiellen Volkerstrafrechts", en: Hankel/Stuby (supra nota 2), pp. 270-294, T. McCormack/G. Simpson, "The International Law Commission's Draft Code of Crimes against the peace and Security of Mankind: An Appraisal of the Substantive Provisions", CLF vol.5, No 1 (1994), pp. 1 a 55.

6 CDI, 48a. Sesión, 6/5 al 26/7/96, UN-Doc. A/CN.4/L.532.

7 Ver el Informe del Comité $A d$ Hoc para el Establecimiento de un Tribunal Penal Internacional permanente, AG, registros oficiales, 50a Sesión, Suplemento $N^{\circ} 22$ (A/50/22).

8 Proyecto de Informe en "General Principles of Criminal Law", NU-Doc. A/AC.249/ CRP.9, 4/4/96; ver, asimismo, Lehtonen, IELR 1996, pp. 274 a 276.

9 Ver el Informe del Comité de Preparación del Establecimiento de un Tribunal penal internacional permanente, AG, registros oficiales, 51 a Sesión, Suplemento $N^{\circ} 22(A / 51 / 22$ y Add. 1). Ver también los trabajos de prensa en: ¡Error!No se encuentra el origen de la referencia. (Internet).

10 Association Internationale de Droit Pénal (AIDP)/International Institute of Higher Studies in Criminal Sciences (ISISC)/Max Planck-Institute fur aulandiches und internationales 
yecto alternativo fue luego ampliado con un proyecto de "Parte general" donde, en 21 artículos, se describen las previsiones más relevantes que una ley penal puede contener en una parte general. ${ }^{11}$ Muchas de las propuestas fueron adoptadas por la Comisión Preparatoria ${ }^{12} \mathrm{e}$ influyeron en la redacción de la versión final del Proyecto de Código de 1996. El cuadro comparativo que se agrega al final de este trabajo nos brinda una visión de las más importantes previsiones del Estatuto del Tribunal de Yugoslavia, del Proyecto de Estatuto de la CDI y del Proyecto alternativo.

Las consideraciones que se habrán de desarrollar a continuación intentan ofrecer una visión respecto de algunos aspectos procesales y materiales que se presentan en los proyectos mencionados. Debido al tamaño reducido de este trabajo y al número de cuestiones que deben ser consideradas, no ha sido posible examinar todos los problemas con la profundidad necesaria. No obstante, es de esperar que las referencias bibliográficas estimulen al lector a investigar más allá.

\section{El nivel procesal: observaciones sobre un TPIP}

\subsection{Fundamento legal y jurisdicción}

En principio, el fundamento legal de un TPIP puede establecerse de dos maneras diferentes: a) por un tratado internacional; o, b) por una resolución del Consejo de Seguridad de las Naciones Unidas (CS). La ventaja del segundo camino -y que fuera el empleado para los casos

Strafrecht en Freiburg i. Br. (MPI), Proyecto de Estatuto para un Tribunal Penal Internacional - Proyecto alternativo al de la CDI (Proyecto de Siracusa), preparado por un Comité de Expertos, Siracusa/Freiburg i. Br., julio de 1995.

11 El grupo se reunió, por una iniciativa generada en Siracusa (Italia) en diciembre de 1995 y en el M.P.I. de Freiburg i. Br. En enero de 1996 y trabajó sobre las líneas de los "elementos" de una Parte General incluídos en el Proyecto alternativo, supra nota 10 (comentario al Art. 33). Sus participantes fueron: Prof. Eser (Freiburg i. Br.), Prof. Triffterer (Salburg), Prof. Koenig (Michigan, USA), Prof. Lagodny (Dresden), Dr. Ambos and Dr. Best (ambos de Freiburg i. Br.). Una versión modificada del proyecto se pude encontrar en el citado Proyecto de Siracusa Siracusa/Freiburg/Chicago, 15/3/96, Art. 33-1 a 33-18 y 47 a 47-2. La versión original se puede obtener del autor. Ver también Triffterer, "Österreichs Verpflichtungen zur Durchsetzung des Völkerstrafrechtsn, ÖJZ 1966, pp. 321 a 343, p. 326.

12 Ver, principios generales, supra nota 9. 
de Yugoslavia y Ruanda- es evidente. Permite establecer un TPIP como órgano subsidiario del CS sólo con la aprobación de nueve de sus quince miembros, incluidos los cinco permanentes (Art. $27^{\circ}$ III de la Carta de las Naciones Unidas). ${ }^{13}$ De esta manera, no hay necesidad para largas negociaciones o interminables compromisos sustantivos. ${ }^{14}$ No obstante, y pese a la practicidad de este punto de vista, el fundamento legal de esta clase de tribunal es cuestionable desde la perspectiva del Derecho Internacional Público. ${ }^{15}$ Sin embargo se puede argumentar seriamente que en caso de graves violaciones a los derechos humanos existe el deber y no sólo el derecho de perseguirlas (que puede ser realizado aún en contra de la voluntad del Estado involucrado si no demuestra intención de perseguirlas adecuadamente). ${ }^{16}$ La legiti-

13 Respecto de la distinción entre procedimiento y otras cuestiones en el sentido del Art. $27^{\circ}$ II y III de la Carta de las UN ver Simma/Brunner, sobre el Art. 27, notas marginales 11 y ss., en Simma (ed.). Charta der Vereinten Nationen, Kommentar, München 1991. Resoluciones basadas en Cap. VII, por ello, no son cuestiones de procedimientos de las mencionadas en el sentido del Art. $27^{\circ}$ II, pero siempre requieren de la mayoría calificada del Art. $27^{\circ}$ III de la Carta de la ONU (Ibid., nota marginal 13). Por otro lado, uno puede considerar el establecimiento de un órgano subordinado, en principio, como una decisión procesal, pero el Art. $29^{\circ}$ sólo ofrece competencia organizativa y no sustantiva Hilf, Art. $29^{\circ}$, nota marginal 27 y Bothe, Art. 38 $8^{\circ}$, nota marginal 39 en: Simma, supra. Sólo cap. VII otorga esta competencia tornando, igualmente, la cuestión en "otra" (cuestión) dentro del sentido del Art. 27० III.

14 Estos han sido los argumentos más importantes, en el caso de la antigua Yugoslavia a favor del modelo del CS. Ver O'Brien, supra nota 2 ps. 643: «[...] un tratado puede ser incierto y lento [...]» o Shraga/Zacklin, supra nota 2, ps. 361: "[...] llevaría años.» También R.A. Kolodkin, "An ad hoc international tribunal for the prosecution of serious violations of international humanitarian law in the Former Yugoslavia», CLF vol. 5, $N^{\circ} 2-3$ (1994), pp. 381 a 399, 385 y ss., 391: «[...] el establecimiento [...] por el sentido de una resolución del Consejo de Seguridad se presenta para la mayoría de los analistas como la opción que mejor responde a las demandas legales y a las necesidades prácticas de la situación".

15 Es particularmente incierto determinar de dónde se deriva la competencia del CS para someter actos cometidos en el territorio de un Estado, y en el marco de un poder jurisdiccional, a un Tribunal penal internacional sin interrogar al Estado acerca de si acepta o no esa sumisión por la vía de un acto formal de cesión o transferencia (Ver S. Oeter, "Kriegsverbrechen in den Konflikten um das Erbe Jugoslawiens. Ein Beitrag zu den Fragen der kollektiven und individuellen Verantwortlichkeit für Verletzungen des Humanitären Völkerrechts", en: ZaöRV 53 (1993), pp. 2 a 48, 34 y ss.; Oellers-Frahm, supra nota 2, pp. 417, 418). Para críticas adicionales, desde el punto de vista serbio, ver D. Cotic, "Introduction", CLF vol. 5 , No 2-3 (1994), pp. 223 a 236, 233.

16 Ver Oellers-Frahm, supra nota 2, pp. 417, C. Tomuschat, "International criminal prosecution: the precedent of Nürnberg confirmed". CLF vol. 5, No 2 y 3 (1994), pp. 237 a 247. esp. 241 y 242 (también para el establecimiento sobre la base del cap. VII de la Carta de la $\mathrm{ONU})$. Para más detalles respecto a las obligaciones de perseguir ver también $\mathrm{K}$. Ambos, 
midad de un TPIP depende, básicamente, del reconocimiento que de su jurisdicción hagan el mayor número de Estados posibles. La aceptación global constituye un pre-requisito indispensable que habrá de redundar en el efectivo cumplimiento de las sentencias que se dicten. Frente a estos antecedentes, el modelo del CS se presenta como una especie de medida de coerción que sólo se justifica en casos excepcionales que reclaman de una jurisdicción ad-hoc para satisfacer una situación manifiesta de necesidad internacional (como ocurrió en el caso de Yugoslavia) o cuando la demanda proviene de un nuevo gobierno (como ocurrió en el caso de Ruanda). De hecho el establecimiento de un tribunal internacional ad-hoc se puede fundar en el Capítulo VII de la Carta de las Naciones Unidas con argumentos bastante convincentes. ${ }^{17}$ Por otro lado, el modelo del tratado no prevé el establecimiento de un TPIP como un órgano de la ONU, más bien -y en ello reside una importante diferencia-, requiere que ese tribunal se establezca como un órgano adicional al resto de los de la ONU y sobre la base de un tratado (así como ocurre con la CIJ; comparar el Art. $7^{\circ}$ parágrafo 1 de la Carta de las Naciones Unidas con el Art. $1^{\circ}$ del Estatuto de la CIJ).$^{18}$ Con base en los recientes comentarios formulados por los representantes de las delegaciones ante el Comité ad-hoc de la ONU, parece claro que un tribunal de esas características sería establecido como un "órgano judicial independiente originado en un tratado multilateral». ${ }^{19}$

En segundo lugar, surge la pregunta acerca de la jurisdicción por razón de la materia del TPIP (subject matter jurisdiction). ¿Sólo deben

Straflosigkeit von Menschenrechtsverletzungen. Zur «impunidad» in südamerikanischen Staaten aus völkerstrafrechtlicher Sicht (con sumario en inglés), Freiburg/Br. (Max-Planck-Institut für auständisches und internationales Strafrecht), 1997, pp. 163 y ss. (próximamente publicada en castellano por CIEDLA, Buenos Aires, de. Dyke, Medellín, y por la Comisión Andina de Juristas, Lima).

17 Cf. International Criminal Tribunal for the Former Yugoslavia (Appeals Chamber), Decision in Prosecutor vs. Dusko Tadic, 2/10/95, en 35 I.L.M. 32 (1996), 32 y ss. (También HRLJ 1995, 437). Para un análisis crítico que se ocupa de la base legal ver: J.E. Alvarez, "Nuremberg revisited: The Tadic case», 7 EJIL (1996), pp.245 a 264.

18 Ello, ciertamente, requiere de una modificación de la Carta de las Naciones Unidas (Jaenicke, en cuanto al Art. $7^{\circ}$, nota marginal I y s., en: Simmo, supra nota 13; Schutte, supra nota 2, p. 447)

19 Informe del Comité ad hoc, supra nota 7, par. 15; cf. También Crawford, 1995, supra nota 4, pp. 409 y 410. 
estar incluídos aquellos crímenes que "pertenecen sin duda alguna al Derecho consuetudinario» ${ }^{20}$-como lo estatuyó el CS y con algo más de extensión como lo hizo la CDI y el Proyecto Alternativo (Art. 20 parágrafo 1)- o sólo los delitos tipificados en los instrumentos internacionales? ${ }^{21}$ En este punto existe una relación inversamente proporcional entre el número de hechos incluídos y el número de países aceptantes: a mayor cantidad de conductas incluídas bajo esa jurisdicción menor será el número de países que querrán aceptarla. ${ }^{22}$ Este problema puede ser reducido remitiendo todos los delitos que (únicamente) se encuentran reconocidos por tratado a una jurisdicción ad hoc con la consecuencia de que las partes en el Estatuto puedan, todavía, decidir si desean aceptar la jurisdicción del TPIP caso por caso. La jurisdicción más importante (inherente/originaria) exclusiva que implica una aceptación ipso facto de la jurisdicción del TPIP con el acto por el que se es parte del Estatuto debe limitarse a los crímenes más importantes que conciernen a la comunidad internacional. Esta es la posición de la $\mathrm{CDI}^{23}$ y la de la mayoría de los Estados que participan en el actual debate. ${ }^{24}$ Es prácticamente una salida de compromiso entre lo políticamente posible en lo inmediato y los objetivos legales a largo plazo: «Podemos comenzar con el establecimiento de un tribunal con un modesto esquema de jurisdicción, con la expectativa de que algún

20 Doc. NU S/25704, par. 34. Esto incluye los delitos referidos en las notas 85 a 103. Uno debe recordar que el correspondiente Art. 2-5 del Estatuto de Yugoslavia no creó derecho sustantivo sino que sólo definió el alcance de la materia sujeta a la jurisdicción del Tribunal (Tomuschat, supra nota 16, pp. 242 a 243).

21 Así Bassiouni, supra nota 1, pp. 33 y ss. Ver también Art. $20^{\circ}$ par. 2 Proyecto de la CDI y Art. $20^{\circ}$ Proyecto Alternativo, supra nota 6610, con anexo que omite incluir algunos delitos mencionados en los tratados en adición a los cuatro grupos de delitos (ver notas 87 y ss.).

22 Por ello, hubo consenso en la XIV Conferencia de Derecho penal internacional en que "la competencia de un tribunal de esa clase debería encontrarse limitada a los delitos internacionales políticamente menos importantes" (O. Triffterer, "Die völkerrechtlichen Verbrechen und das staatliche Strafrecht", en: Zeitschrift für Rechtsvergleichung 30 (1989), pp. 83 a 628 , esp. 123).

23 Ver parágrafo 2 del preámbulo del Proyecto de la CDI: «Enfatizando que un tribunal de esa clase es concebido para ejercer su jurisdicción sólo respecto de los delitos más serios que conciernen a la comunidad internacional como un todom: (resaltado en el original; Informe de la CDI, supra nota 4, par. 91, pp. 44).

24 Cf. Informe del Comité ad hoc, supra nota 4, par. 54, 91; Crawford, 1995, supra nota 4, p. 410 . 
día se convierta en la clase tribunal internacional que muchos de nosotros deseamos». ${ }^{25}$ La jurisdicción ad hoc tendrá la función de ir ganando la confianza de los Estados y de convencerlos de la necesidad de establecer un TPIP a fin de obtener la aceptación general de su jurisdicción a largo plazo. ${ }^{26}$

No obstante, la mera referencia a instrumentar un tratado internacional no es convincente y encierra el riesgo de minimizar la función del tribunal. ${ }^{27}$ Este método, la llamada "propuesta-tratado", puede incurrir en contradicciones si el carácter convencional de un crimen en particular se considera como la base o el indicio decisivo. Hay crímenes que no se encuentran reconocidos por la comunidad internacional a pesar de su codificación en tratados internacionales como, por ejemplo, las actividades mercenarias. Asimismo, también hay crímenes previstos en los tratados que son menos graves que otros no incluídos pero que, sin embargo, se encuentran reconocidos en el Derecho Internacional consuetudinario. A pesar de ello, estos crímenes no incluidos en los tratados -de acuerdo con la «propuesta tratadow- no estarían dentro de la jurisdicción del TPIP. Por ejemplo, Bassiouni incluye dentro de la jurisdicción "crímenes» convencionales relativamente menores y prácticamente irrelevantes, como «delitos contra la navegación civil internacional», "delitos de drogas" ${ }^{28}$ y «co-

25 Bassiouni, supra nota 1, p. 19 (traducción del inglés). Ver también ibid., pp. 57 y ss., el comentario del Art. $19^{\circ}$ del Proyecto Bassiouni; allí se sostiene, correctamente, que la jurisdicción exclusiva originaria es "la dificultad política más difícil de superar» (p. 59).

26 Ver Bassiouni, supra nota 1, p. 61: «Este enfoque crea un aliciente para los Estados/ partes a experimentar con la jurisdicción del Tribunal y eventualmente a ganar la confianza necesaria para acudir más frecuentemente al Tribunal». (Traducción del inglés).

27 Cf. Inofrme del Comité ad hoc, supra nota 7, parágrafo 81.

28 Ver también el apéndice II en cuanto al Art. $20^{\circ}$ e) del Proyecto de la CDI, incluso Art. $3^{\circ}$ (I) de la Convención de Viena sobre Drogas de 1988 (Informe de la CDI, supra nota 4, parágrafo 91, pp. 155 a 157). Esta previsión no hace más que establecer una distinción respecto de las diversas conductas que abarcan desde el cultivo, la mera posesión y el tráfico, con consideraciones sobre la sustancia -drogas blandas o duras-. Más allá, las convenciones existentes en materia de drogas no contienen normas lo suficientemente claras para ser aplicadas (ver K. Ambos, Die Drogenkontrolle und ibre Probleme in Kolumbien, Peru und Bolivien -eine kriminologische Untersuchung aus Sicht der Anbauländer, unter besonderar Berücksichtigung der Drogengesetzgebung, Freiburg/Br. 1993, p. 128). Someter los delitos de drogas a la jurisdicción de un TPIP no sólo conduciría a una devaluación del concepto de delito sino que, inmediatamente, a un congestionamiento de trabajo. (Cf. Crawford, 1994, supra nota 4, p. 146 y Bassiouni, en: igual, supra nota 1, pp. 98 y 99). 
mercio internacional de materiales obscenos", pero no incluye ejecuciones ilegales y desaparición de personas. ${ }^{29} \mathrm{El}$ argumento meramente formal acerca de que en los últimos tratados los crímenes mencionados en segundo lugar no se encontraban previstos es inconcebible; por su gravedad ya se encuentran comprendidos dentro del Derecho Internacional consuetudinario y son materia de persecución y castigo. ${ }^{30}$ Más aún, algunos delitos tipificados en los instrumentos internacionales son frecuentemente muy vagos como para poder ser directamente aplicados en el Derecho nacional; es por ello que se requiere de un proceso interno de transformación. ${ }^{31}$ Si uno desea incluir todos los crímenes reconocidos internacionalmente no se debe limitar a los tratados internacionales. Lejos de ello, es mucho más consistente extender la materia que se encontrará sujeta a la jurisdicción del TPIP sólo a aquellos crímenes cuyo reconocimiento por el Derecho Internacional general, incluída la costumbre internacional, se encuentra fuera de toda discusión, con independencia de su tipificación en instrumentos internacionales. ${ }^{32}$ Esta propuesta no implica una disminución cualitativa frente al aumento cuantitativo de la "propuesta tratado"; en especial si los crímenes contra la humanidad, reconocidos en todos los estatutos, son interpretados de manera amplia. En conclusión, la propuesta combinada que realizan tanto la CDI como en el Proyecto Alternativo (Art. $20^{\circ}$ ) se presenta como más convincente. ${ }^{33}$ Adoptar

29 Los 24 "delitos" mencionados en el Proyecto de Bassiouni se basan en 316 instrumentos internacionales (Bassiouni, supra nota 1, p. 40). Respecto a la necesidad de distinguir entre delitos internacionales de una manera más limitada en este contexto, ver, también, Triffterer, supra nota 22, pp. 103 a 112 (criticando la ausencia de diferenciación en el proyecto de Bassiouni de 1980).

30 Ver referencias en la nota 16.

31 Ver Crawford, 1994, supra nota 4, p. 143.

32 Sin embargo, ello genera otros problemas debido a que el número y el contenido de los delitos internacionales reconocidos se encuentra altamente debatido. Por ello, el "Grupo de Trabajo" de la CDI fue de la opinión que ulas posibles controversias sobre la identificación o contenido de los delitos alcanzados por la ley internacional requieren de un tratamiento con mayores precauciones que aquellas dadas a los delitos basados en tratados [...]" (Crawford, 1994, supra nota 4, p. 145).

33 La inclusión del «delito" de "agresión", sin embargo, se presenta como problemática. La disputa en torno a la definición de agresión impidió que la CDI pudiera trabajar por más de 20 años. Como la resolución correspondiente de la AG tampoco clarifica este punto, el Proyecto de la CDI determina que un reclamo sobre la base de una agresión requerirá de una resolución constitutiva del CS Art. 23 Par. 22 i.V.m. 20 Par.21 (b); ver también Crawford, 1994, supra nota 4, p. 147; Graefrath, supra nota 2, pp. 305 y ss. y más adelante nota 75. 
esa propuesta es, por razones de certeza, seguramente, preferible a incluir en un anexo al Estatuto la lista de los crímenes incluídos en los tratados. ${ }^{34}$

Un punto posterior a considerar es el de la relación entre el TPIP y las jurisdicciones nacionales. La CDI sigue el «principio de complementariedad" estableciendo en su preámbulo que el TPIP debe «ser concebido como complementario al sistema de administración de justicia nacional en aquellos casos en los que el proceso judicial no sea viable o no sea efectivo". ${ }^{35}$ Aunque el principio forma parte del contexto en el que el Estatuto debe ser interpretado, sus consecuencias prácticas no son muy claras. Esta cuestión, que es central, sólo ha sido señalada de forma indirecta dentro del texto del Proyecto ${ }^{36}$ (Art. 35\%). Consecuentemente, algunos Estados entienden que es «una fuerte presunción en favor de las jurisdicciones nacionales" y otros, no. ${ }^{37} \mathrm{La}$ pregunta clave es la de determinar en qué casos el TPIP habrá de "complementar" la jurisdicción nacional o, para utilizar las palabras de la CDI: ¿cuándo un procedimiento judicial no es «viable» o «efectivo»? La cuestión se encuentra íntimamente relacionada con la de la jurisdicción de un TPIP por razón de la materia y con el papel que la jurisdicción nacional puede jugar en el caso concreto. Extremando las consecuencias del principio de complementariedad se puede afirmar que la jurisdicción del TPIP se reducirá a unos pocos delitos especialmente graves ("hard core crimes»). ${ }^{38}$ En estos casos, la intervención del TPIP dependerá del funcionamiento del respectivo sistema de administración de justicia penal nacional. Si no funciona en absoluto, por ejemplo, si no existe la capacidad ni la voluntad de investigar seriamente, la jurisdicción del TPIP puede ser invocada. $\mathrm{Si}$, en principio, la administración de justicia nacional «funciona», por ejemplo, si investigaciones, más o menos serias, con iniciadas, el problema que se presenta como de difícil solución es el de poder establecer la línea que separa una investigación «suficiente» de otra «insuficiente», ya que la

34 Ver, por ejemplo, la lista del Art. $20^{\circ}$ e) del Proyecto de la CDI referido a 14 tratados (Informe de la CDI, supra nota 4, Par. 91, pp. 147 a 161).

35 Informe de la CDI, supra nota 4, Par. 91, p. 44 (traducción del inglés).

36 Cf. Art. $31^{\circ}$ de la convención de Viena sobre los Tratados (Doc NU. A/Conf.39/ 11 add.2, 1971, p. 287).

37 Informe del Comité ad hoc, supra nota 7, parágrafos 29 a 37 (traducción del inglés).

38 Sobre estos delitos ver infra notas 92 y ss. 
segunda determinará la competencia del TPIP. En el comentario que la CDI realiza en el preámbulo se establece que «[...] se entiende que operará en aquellos casos donde no existan perspectivas [...] de que las personas sean llevadas efectivamente a juicio ante las cortes nacionales». ${ }^{39}$ Los Estados sólo señalaron que «la intervención del tribunal donde se encuentre funcionando un sistema de administración de justicia (pero) que es utilizado como una pantalla, requiere de consideraciones muy cuidadosasm. ${ }^{40}$ De aquí se puede concluir que deberemos enfrentarnos a un TPIP ${ }^{41}$ complementario o "suplementario", cualquiera que sea el verdadero significado del término.

\subsection{Procedimiento y otras reglas ${ }^{42}$}

Las reglas de procedimiento siguen el sistema acusatorio en tanto el órgano de persecución investiga y prepara la acusación. El tribunal, por su parte, interviene en una especie de procedimiento intermedio, a más tardar tras la presentación de la acusación. En un modelo "tratado» se presenta la cuestión acerca de si el CS por sí, independientemente de un Estado miembro, puede iniciar procedimientos sobre la base de una medida enmarcada dentro del capítulo VII de la Carta de la ONU. ${ }^{43}$ Uno puede sentirse escéptico sobre la legitimidad de una acción de esa clase pero, en principio, no puede ser absolutamente excluída si se desea evitar la creación paralela de tribunales ad hoc por el CS en aquellos casos donde entienda que el TPIP no ha tomado la debida consideración de sus intereses. ${ }^{44}$ La cuestión juega un papel importante para los procedimientos futuros ya que -por lo menos de acuerdo al Proyecto de la CDI (Art. 230 Par. 3)- un procedimiento que se originó debido a una situación enmarcada dentro del capítulo

39 Informe de la CDI, supra nota 4, parágrafo 91, p. 44 (traducción del inglés); ver también Informe del Comité ad hoc, supra nota 7, parágrafo 42.

40 Informe del Comité ad hoc, supra nota 7, parágrafo 45.

41 Crawford, 1995, supra nota 4, p. 415.

42 Ver el debate en general en el Comité ad hoc (Informe, supra nota 7, parágrafo 128 a 194).

43 Ver Art. 25० Par. 4 en conjunción con el Art. 23 Proyecto de la CDI; en forma similar en el Proyecto Alternativo supra nota 10. Para una visión crítica ver Graefrath, supra nota 2, pp. 307 y ss.

44 Cf. Crawdord, 1995, supra nota 4, ps. 413; Informe del Comité ad boc, supra nota 7. parágrafo 120 . 
VII, no se habría iniciado sin la previa autorización del CS. Con carácter general la cuestión más importante a resolver consiste en lograr un equilibrio correcto entre la necesaria independencia del TPIP y el papel protagónico que el CS tiene en el mantenimiento de la paz y la seguridad a nivel internacional. Debe mencionarse que los Estados han sido particularmente críticos sobre el ejercicio de una jurisdicción exclusiva por parte del CS en los casos de agresión (Art. $23^{\circ}$ Par. 2 del Proyecto de la CDI). 45

En todos los otros casos, el fiscal debe probar prima facie que existe un caso y el tribunal debe determinar la admisibilidad de la acusación. No obstante, la CDI no ha previsto una definición para saber cuándo nos encontramos, prima facie, ante un caso. Debe recordarse que la mera acusación representa una seria injerencia en los derechos de la persona afectada; por ese motivo, la interpretación de cuándo nos encontramos, prima facie, ante un caso debe ser restrictiva. Por ese motivo, correctamente, el Proyecto alternativo lo definió como un estado «de credibilidad tal que pueda -si no es contestado por la defensa- ser base suficiente para condenar al acusado" (Art. $2^{\circ} \mathrm{Pa}$. 2, trad. del inglés). Esta definición es similar a la denominada sospecha vehemente (dringender Tatverdacht) utilizada en la Ordenanza Procesal Penal alemana (Strafprozessordnung) como un requisito de la acusación.

Más adelante, el Art. $37^{\circ}$ parágrafo 4 del Proyecto de la CDI prevé el establecimiento de una "cámara de acusación" especial que, sin embargo, no se encuentra en las previsiones generales relativas a las cámaras (Art. 90). La función de esta cámara consistiría en llevar adelante un proceso escrito de evaluación de pruebas. El resultado de este «sumario» o «expediente de pruebas» puede ser utilizado en el juicio posterior. Este procedimiento es peligroso para el acusado y por ello sólo debería ser admitido si existió asistencia jurídica. ${ }^{46}$

El orden de la etapa del juicio tiene similar importancia. La lectura de la acusación y el informe, así como el examen personal y la declaración del acusado, se deben realizar antes de que se presenten las pruebas. La presencia del acusado es especialmente significativa para su

45 Ver recientemente la discusión en el Comité ad hoc (Informe, supra nota 7, Par. 71, pp. 120 a 126).

46 Art. $37^{\circ}$ parágrafo 4 del Proyecto Alternativo supra nota 10. Cf. Informe del Comité ad hoc, Supra nota 7, parágrafo 168. 
defensa. Son posibles diferentes soluciones. El Proyecto de la CDI y de manera más restringida- el del Proyecto alternativo permiten el juicio in absentia (Art. 37० Par. 2); ${ }^{47}$ no así los Estatutos para la antigua Yugoslavia y Ruanda. Por razones prácticas, un juicio in absentia no puede ser prohibido de manera absoluta; ello, sin perjuicio de que las críticas legales y políticas que puedan suscitarse deben ser tomadas con la debida seriedad. ${ }^{48}$ En todo caso, las excepciones sólo deben ser permitidas bajo circunstancias claramente establecidas. El papel correcto del tribunal -activo como en el sistema mixto- instructorio (instruktorisch) o pasivo como en el sistema de partes (adversarial system) puro- es otro tema de discusión. ${ }^{99}$ Por último, debería llegarse a una combinación de los dos sistemas dominantes -el sistema de partes anglonorteamericano y el continental mixto-.

Todos los estatutos separan la etapa de juicio -concerniente a la culpabilidad del acusado- de la etapa de sentencia (Schuldinterlokut). Los que se encuentran a favor de esa clase de separación tienen en cuenta que ello evita que el tribunal -normalmente un jurado- decida respecto de la cuestión de culpabilidad incorrectamente influido por información relativa a las circunstancias personales del acusado (información que sólo es requerida a efectos del dictado de la sentencia); sin embargo, el TPIP no es un jurado y no puede sostenerse seriamente que ninguna información relativa a las circunstancias personales del

47 El Art. $37^{\circ}$ parágrafo 2 del Proyecto de la CDI admite un juicio in absentia sólo como excepción [(a) "por razones de seguridad o de enfermedad», (b) «el acusado continuamente impida la celebración del juicion, (c) «Se ha fugado]. El Art. 37० Par. 2 del Proyecto Alternativo, supra nota 10, es más restrictivo, admitiendo el juicio in absentia sólo si «(a) el acusado expresamente a eludido su derecho de comparecer; (b) [...] continuamente impide el juicio; (c) luego del comienzo del juicio [...] se ha fugado de su custodia legal [...] o ha violado los términos de su caución'.

48 De acuerdo con el Comité de Derechos Humanos de la ONU, el Art. 14\% (3) (d) de la Convención Internacional de Derechos Civiles y Políticos no prohibe un juicio in absentia si todo se realizó para informar y notificar debidamente al acusado (ver Mbenge v. Zaire, No 16/1977, Decisiones seleccionadas del Comité de Derechos Humanos bajo el Protocolo Opcional, vol. 2, UN-Doc. CCPR/C/OP/2, at 76ff.; ver también el Tribunal Europeo de Derechos Humanos en Colozza v. Italy, 89 Eur. Ct. H.R., ser. A, 1985). Ver también el Informe del Comité ad hoc, supra nota 7, Par. 164 a 167.

49 Ver la diferenciación en: W. Perron, "Rechtsvergleichender Querschnitt», del mismo (ed.), Die Beweisaufnahme im Strafverfahrensrechts des Auslandes, Freiburg (Beiträge und Materialien aus dem Max Planck Institut für auständisches und internationales Strafrecht) 1995, pp. 560 a 567. 
acusado llegará a conocimiento de los jueces de un tribunal internacional o que esa clase de jueces puedan ser influidos negativamente por esta vía. Por ello, la división del juicio en dos etapas se presenta como innecesaria.

Dada la ausencia de normas internacionales referidas al ámbito de las penas uno debe referirse a la ley nacional. ${ }^{50}$ Es altamente improbable que existan niveles comunes en el plano internacional. Por ello, la mera referencia al encarcelamiento o a la multa como clases de pena (cf. Art. $47^{\circ}$ del Proyecto de la CDI) sin especificar su duración o monto, puede lesionar el principio de nulla poena. ${ }^{51}$ En este contexto, se presenta la cuestión general de la ley aplicable. Sólo habrá una solución satisfactoria si la ley aplicable en un caso particular se encuentra vinculada a la jurisdicción correspondiente al caso o si el propio Estatuto determinó claramente cuál es la ley aplicable. El CS ignoró esta cuestión en los Estatutos de los 'Tribunales ad-hoc. El proyecto de la CDI lo ha previsto pero de manera poco satisfactoria. Es poco clara la referencia a «este Estatuto; los tratados aplicables y los principios y reglas del derecho internacional» (Art. 33a), b)), si, por otra parte, la discusión en torno a la delimitación de la materia que se encontrará sujeta a jurisdicción, demuestra que el número de leyes criminales universalmente reconocidas es muy limitado. Aún menos convincente es la referencia a "[...] toda regla del derecho nacional [...] aplicable extensivamente» (Art. $33^{\circ} \mathrm{c}$ )): la cuestión es determinar con qué extensión la ley nacional es aplicable en un caso concreto. ${ }^{52}$ El Proyecto alternativo al menos expone genéricamente sus reparos

50 Esto es evidente si, como en el caso yugoslavo, el Estado afectado ha transformado los tratados internacionales en su derecho interno y ha establecido las correspondientes directrices para el dictado de sentencias. No obstante, desafortunadamente, el estatuto no se refiere a estas directrices para las sentencias sino sólo para la práctica en general (OellersFrahm, supra nota 2, p. 427).

51 El Proyecto Alternativo, supra nota 2, al menos prevé una sentencia mínima de no menos de un año y una multa apropiada. Ver también el Informe del Comité ad hoc, supra nota 7, Par. 187 a 190. No obstante, la doctrina dominante considera que el principio de nulla poena sólo requiere el establecimiento de una pena genérica; una indicación concreta de la clase, extensión o monto no es necesaria (cf. Triffterer, Bestandsaufnahme zum Völkerstrafrecht, en: Hankel/Stuby, supra nota 2, pp. 169 a 269, allí también 218 y 219).

52 Para los comentarios críticos de los estados cf. Informe del Comité ad hoc, supra nota 7, Par. 52/53. 
del problema refiriendo, en este contexto, «a las cuestiones abiertas y elementos que deben ser regulados en una Parte Generalm. ${ }^{53}$

Respecto de la ejecución de la sentencia se puede presentar la situación de que ningún Estado quiera alojar al sentenciado. ¿Quién querrá hacerlo con criminales como Karadzcic, líder de los serbio-bosnios o como el -recientemente fallecido- traficante de drogas colombiano Pablo Escobar? Para estos casos ningún estatuto presenta una solución convincente. A largo plazo es posible que la CDI establezca sus propias instalaciones penitenciarias en áreas extraterritoriales; no obstante, incluso bajo estas circunstancias, el país afectado deberá consentir los encarcelamientos dentro de su territorio. ${ }^{54}$

La referencia a liberaciones o previsiones de atenuación de la pena a nivel nacional implica el peligro de poder burlar la sentencia impuesta por el TPIP. Por ese motivo, en el Estatuto se deben incluir limitaciones derivadas del Derecho Internacional. Una remisión absoluta de una sentencia en casos de graves violaciones a los derechos humanos no puede ser permitida. ${ }^{55}$ En todo caso, las decisiones relativas a concesiones parciales de disminución de la pena deberían ser tomadas por el propio TPIP. ${ }^{56}$

Más allá de los problemas teóricos y técnicos implicados, uno no debe perder de vista que el tema central en todo sistema procesal es de naturaleza político criminal: garantizar el apropiado equilibrio entre los derechos del imputado, o acusado, y la eficiencia de la persecución. Afortunadamente, parece existir consenso entre los Estados involucrados en este debate para que ese equilibrio sea asegurado. ${ }^{57}$

53 Proyecto Alternativo, supra nota 10 , comentario al Art. $33^{\circ}$ (trad. del inglés). Estos elementos fueron volcados en términos concretos a comienzos de 1996 (supra nota 11).

54 Esta es la tendencia del Proyecto Bassiouni como se sostiene en el comentario al Art. 28: «El Tribunal podrá también alojar a sus condenados en sus propios centros de detención, que podrán ser establecidos por la Convención de conformidad con un acuerdo de alojamiento entre el Tribunal y el Estado donde el centro de detención se establezcan (Bassiouni, supra nota 1, ps. 79).

55 Ver Ambos. Supra nota 16, pp. 209 y s.

56 Art. $60^{\circ}$ del Proyecto Alternativo, supra nota 10.

57 Informe del Comité ad hoc, supra nota 7, Par. 132. 


\section{El nivel sustantivo: observaciones sobre un Código Penal Interna- cional}

\subsection{Parte general}

El concepto de delito utilizado en el Proyecto de Código de 1991 fue una marcada indicación de su carácter político. ${ }^{58}$ En lugar de establecer una definición clara el Art. $1^{\circ}$ se refiere a «delitos (bajo la ley internacional)m. El Proyecto de Código de 1996, aunque no establece una clara definición, constituye un avance porque se refiere a los crímenes definidos en la parte especial y estos delitos han sido sustancialmente reducidos. Amenaza de agresión, intervención, dominación colonial, mercenarios y comercio ilícito de drogas han sido excluídos [para más detalles infra parte 2)].

La cuestión de cómo las circunstancias subjetivas de un acto criminal («motivos» en el lenguaje del Proyecto de Código de 1991 e «intención" en el de 1996) deben ser tratados no ha sido resuelto en forma satisfactoria. Afortunadamente, el Proyecto de Código de 1996 eliminó el confuso Art. $4^{\circ}$ del Proyecto de 1991..$^{59}$ Los elementos subjetivos ahora se encuentran incluídos en las previsiones relativas a la responsabilidad individual por las que un individuo responde si él o ella «intencionalmente cometen esa clase de delito" [Art. 2० Par. 3 (a)]. Ello significa que la responsabilidad presupone, al menos, el dolo general previendo además que ciertos delitos requieren de un dolo específico (en particular el delito de genocidio). Sin embargo, todavía persiste alguna duda ya que el Art. $2^{\circ}$ incluye una serie de previsiones que pueden conducir a atribuir responsabilidad meramente objetiva (por ejemplo, órdenes de comisión, omisión, ayudar, fomentar, participar directamente, incitar, atentar, etc.), sin aclarar si estas conductas requieren, también, de conocimiento y voluntad (dolo). Dado que hubo consenso en la CDI sobre la cuestión de que el dolo era un elemento necesario del delito y el desacuerdo existió únicamente sobre

58 Para la discusión en el marco de la CDI ver el Informe de la CDI, supra nota 4, parágrafos 109 a 117; e Informe de la CDI sobre los trabajos de la 47a Sesión, $2 / 5$ al 21/7/ 95, AG, registros oficiales, 50a Sesión, suplemento No 10 (A/50/10), Par. 47.

59 En el Art. $4^{\circ}$ dice: «la responsabilidad [...] no se verá afectada por otros motivos [...] que no se encuentren alcanzados por el deliton. 
si ello debía ser expresamente explicitado, se puede argumentar que el requisito del dolo es evidente en sí mismo. En efecto, algunos miembros de la CDI consideran a los elementos subjetivos como una parte inherente de los crímenes internacionales y por ello no advierten la necesidad de establecer una norma explícita al respecto, mientras que otros desean incluirla explícitamente en la norma que regula la responsabilidad individual. ${ }^{60}$ Así, la solución propuesta por el Proyecto de 1996 parece ser un compromiso en el sentido de que menciona expresamente el dolo general, pero no lo regula válidamente de mane$\mathrm{ra}$ independiente y general. Con respecto a la conducta negligente el nuevo Art. $2^{\circ}$ parece dejar claro que no debe ser punible. Esto se corresponde con el Proyecto alternativo que incluye como elementos mentales sólo al "conocimiento» y a la «intención" (Art. 33-7).

En el campo de las eximentes (defences) es llamativo que las cuestiones relativas a las órdenes superiores y responsabilidad de los mandos superiores requieran tres artículos $\left(\right.$ Art. $5^{\circ}$ a $7^{\circ}$ ), mientras que otras eximentes no son siquiera mencionadas. Esto se debe, parcialmente, a la experiencia práctica obtenida de los juicios por crímenes de guerra seguidos contra los nazis que mostraron claramente que la orden del superior es la defensa más utilizada. ${ }^{61}$ Otras eximentes ni siquiera han sido consideradas por el Estatuto del Tribunal Militar Internacional (en adelante, Estatuto del TMI) ni por posteriores instrumentos internacionales. ${ }^{62}$ Así, la historia legal ofrece argumentos de peso en favor de dejar al tribunal la decisión sobre la admisión de una eximente «de acuerdo con los principios generales del derecho a la luz de las características de cada delito" (Art. 14º del Proyecto de Código). Es claro

60 Ver $12^{\circ}$ Informe del Relator Especial de la «Part I", Art. 1-14): Doc-NU A/CN.4/ 460 del 15/4/94 (46a Sesión en 1994), Par. 30 y ss.; Informe de la CDI, supra nota 58, Par.49. Sobre los elementos generales del delito ver Triffterer supra nota 51, ps. 219 y ss.; Tomuschat, supra nota 5, pp. 286 y ss.

61 Ver para el Juicio de Nuremberg contra los mayores criminales de guerra: US-GPO, Nazi Conspiracy and Aggression, Washington D.C. 1946-48, 9 vol.; para los doce juicios ante cortes militares de E.U.A. en Nuremberg: Trials of War Criminals before the Nuremberg Military Tribunals under Control Council Law No 10, vol. I-XV, Washington D.C., 19501953; para otros juicios: UN, War Crimes Commission (Comisión de la ONU para los Crímenes de Guerra), Law Reports of Trials of War Criminals, vol. I-XV, London, $1947-$ 1949.

62 Cf. CDI, supra nota 6, pp. 74 y pp. Referidos a genocidio, Convenciones de Ginebra y sobre «apartheid». 
que los defensores querrán -como lo hicieron en Nuremberg y en los juicios posteriores- alegar eximentes provenientes del Derecho nacional. Entonces el tribunal tendrá que decidir sobre la validez general y la aplicación concreta de la eximente. La CDI, sin perjuicio de no mencionarlos en el proyecto, tiene cuatro eximentes en mente; defensa propia, intimidación o coerción, error de hecho y edad del imputado. ${ }^{63}$

La división final entre eximentes (Art. 140 $)$ y circunstancias atenuantes (Art. $15^{\circ}$ ) -introducida para evitar las críticas de la vieja disposición que mezclaba los dos conceptos- ${ }^{64}$ tiene en cuenta que los fundamentos de la justificación pertenecen a los elementos constitutivos del delito mientras que los que rigen en materia de atenuación deben ser considerados en el marco de la sentencia. Una separación posterior entre las eximentes (en relación a la justificación y a la excusa) $)^{65}$-aunque ha sido reconocida y discutida por la CDI- ${ }^{66}$ no han sido consideradas necesarias. De esta manera, continuarán existiendo los problemas estructurales causados por un enfoque que no establece una diferenciación entre justificación y excusa, por un lado, y consideraciones respecto de la sentencia, por otro.

Con respecto a la orden del superior el Proyecto de 1996 enmendó el viejo y confuso Art. $11^{667}$ y tomó en cuenta una propuesta del Drafting Committee (basado en el Art. $8^{\circ}$ del Estatuto del TMI). El Art. $5^{\circ}$ excluye ahora la orden como una razón para la exención del castigo pero prevé la atenuación «si la justicia asi lo requiere" (if justice so requires). El ajuste refleja el Derecho Internacional convencional y consuetudinario en la materia ${ }^{68}$ Sistemáticamente, sin embargo, la eximente basada en la orden del superior se ha convertido en una circunstancia atenuante (cf. Art. $15^{\circ}$ del Proyecto de Código de 1996).

63 CDI, supra nota 6 , pp. 3 y ss.

64 Eser, en: Bassiouni supra nota 5, pp. 48 y ss.; Robinson en: ibid., pp. 199 y ss.; $12^{\circ}$ Informe del Relator Especial, Supra nota 60, Par. 135 y ss.

65 Ver Eser/Fletcher (eds.), Rechtfertigung und Entschuldigung/Justification and Excuse, comparative perspectives, 2 vol., Freiburg 1987 y 1988 (Belträge und Materialien aus dem Max Planck Institut für ausländisches und internationales Strafrecht).

66 Cf. Informe de la CDI, supra nota 4, parágrafos 176 a 190, esp. 179; CDI, supra nota 6 , p. 2.

67 Se encuentra previsto que el actuar bajo una orden no excluye la responsabilidad criminal si «en las circunstancias del momento era posible [...] no cumplir con la orden".

68 Cf. Ambos, supra nota 16, pp. 294 y s. 
El Art. $6^{\circ}$ mantiene la regla de responsabilidad de los mandos superiores (Art. $12^{\circ}$ del Proyecto de Código del 1991) y el Art. $7^{\circ}$ excluye la doctrina del acto del Estado (Art. 13º Proyecto de Código de 1991, basado en el Art. $70^{\circ}$ del Estatuto del TMI).

Desde el punto de vista de los informes del Relator Especial la prohibición de retroactividad (nullum crimen, nulla poena sine lege), con base en los tratados internacionales de derechos humanos ${ }^{69}$ se encuentra fuera de toda discusión. De esta forma, finalmente ha sido adoptado por el Proyecto de Código de 1996 (Art. 130). No obstante, el sentido exacto del principio en el Derecho Penal Internacional no está totalmente claro. ${ }^{70}$ El Art. $13^{\circ}$ parágrafo 2 del Proyecto de Código de 1996 establece que solamente podrá ser perseguido el acto criminal que sea punible en el momento de su comisión «de acuerdo con la ley internacional o nacional», con independencia de la existencia de un TPIP. ${ }^{71}$ Queda todavía una cuestión abierta relativa a qué actos criminales, en concreto -especialmente respecto de los denominados crímenes contra la humanidad-, se encuentran incluídos en esta afirmación general. ${ }^{72}$ De acuerdo al parágrafo 2 del Art. $13^{\circ}$ la punibilidad de un acto en la ley nacional es suficiente. Esto es obviamente correcto ya que la incertidumbre sólo existe respecto de la aplicación de la ley internacional. Ciertamente el Derecho Internacional contemporáneo no requiere de una detallada descripción escrita de una cierta conducta como criminal (como consideran los juristas del Derecho continental). Es suficiente que la ilicitud de una cierta conducta sea universalmente aceptada y, por ello, su castigo no será considerado ilegítimo. Ello fue reconocido en los juicios a los criminales de guerra

69 Ver Art. 15० ICCPR, 7 ECHR, 9 ACHR, 11 II Declaración Universal de los Derechos Humanos y Crawford, 1995, supra nota 4, p. 414.

70 Respecto de la importancia del principio del nullum crimen en el Derecho Penal Internacional ver la obra fundamental de O. Triffterer, Dogmatische Untersuchungen zur Entwicklung des materiellen Völkerstrafrechts seit Nürnberg, Freiburg 1966; recientemente Ambos, Nuremberg revisited. Das Bundesverfassungsgericht, das Völkerstrafrecht und das Rückwirkungsverbot, Strafverteidiger 1997, pp. 39-43. Respecto de los delitos en particular ver notas 87 y ss.

71 Ver también Swart, en: Bassionuni, supra nota 5, p. 187.

72 Ver, por ejemplo, la nueva perspectiva empleada por T. Meron, "International Criminalization of Internal Atrocities", 89 AJIL (1995), pp. 554 a 577, aplicando el principio del nullum crimen a un Art. $3^{\circ}$ común y 11 Protocolo de las Convenciones de Ginebra (pp. 565 a 566 ). 
nazis $^{73}$ y, recientemente, por el Tribunal Europeo de Derechos Humanos. ${ }^{74}$ No obstante, al menos una previsión del Proyecto de Código colisiona con la prohibición de retroactividad. ${ }^{75}$

Por otro lado, a la luz del principio de nulla poena nos debemos preguntar qué grado de claridad y definición deben tener las penas. ${ }^{76}$ El Art. $3^{\circ}$ del Proyecto de Código de 1996 deja la determinación de la pena al criterio del TPIP, sólo fijándole como límite o pauta de determinación que «el castigo sea mensurado en relación a la clase y gravedad del delito".

El Art. $7^{\circ}$ del Proyecto de 1991 excluye la aplicación de la prescripción. Algunos Estados lo han criticado, manifestando que el concepto de delito del Proyecto de Código es demasiado extenso como para justificar la exclusión de la prescripción para todos los delitos regulados. El Relator Especial, por ese motivo, propone su eliminación; ${ }^{77}$ el Proyecto de 1996 siguió esta propuesta. Desde el punto de vista del Derecho Penal Internacional esta decisión es problemática ya que la obligación de perseguir ciertos delitos internacionales puede implicar la exclusión de la prescripción. ${ }^{78}$ Por ese motivo, en vez de eliminar el artículo, la solución que diferencia los delitos de acuerdo a su gravedad ${ }^{79}$ se presenta como más convincente.

73 Ver UN-War Crimes Commission, supra nota 61, 1949, vol XV, pp. 166 a 170.

74 Informe ECHR reports, series A, vol. 335-B y 335-C (SW v. UK; CR v. UK); cf. Ch Greenwood, "International Humanitarian Law and the Tadic casen, 7 EJIL (1996), ps. 265 a 283, ps. 281; Meron, supra nota 72.

75 El Art. $16^{\circ}$ refiere al delito de agresión (ver también notas 33 y 103). El CS determina -de acuerdo con el Proyecto de Estatuto de la CDI- su existencia. Esta determinación, no obstante, debe tener lugar luego de la comisión de la agresión, por ej. elementos constitutivos del acto se producen retroactivamente (ver. A. Eser, en: Bassiouni, supra nota 5, ps. 45 y Swart, en: ibid., pp. 188, 189; Tomuschat, supra nota 5, p. 278). Para la discusión crítica ver el Informe de la CDI, supra nota 58, parágrafo 67 a 70 . Respecto de la violación del principio del nullum crimen por el Estatuto de Yugoslavia desde la perspectiva eslovena ver: Dolene, supra nota 58, pp. 458 y 459.

76 Ver lo dicho en supra nota 51.

77 12a Informe del Relator Especial, supra nota 60, Par. 81.

78 Explícitamente para el genocidio, crímenes de guerra y crímenes contra la humanidad, cfr. la correspondiente Convención de la ONU del 26/11/68 (UNTS volumen 754, p. 73); ver también el $12^{\circ}$ Informe del Relator Especial, supra nota 60 , parágrafo 78 y ss.

79 Ver Bassiouni, en: el mismo, supra nota 5, p. 163. La discusión inicial de la CDI también tomó esta dirección (cf. Informe de la CDI, supra nota 4, parágrafo 147/153, esp. $151,152)$. 
Las previsiones restantes se ocupan, en cierta medida, de cuestiones procesales. El Art. $1^{\circ}$ que establece garantías procesales se encuentra basado en el Art. $14^{\circ}$ del TPIP y es similar al Art. $41^{\circ}$ del Proyecto de la CDI. Esencialmente se garantiza el juicio justo (fair trial). La regulación del principio ne bis in idem en el Proyecto de Código de 1991 (Art. $9^{\circ}$ ) ha generado muchas críticas. Ello se encuentra íntimamente ligado al principio de complementariedad antes mencionado debido a que, indirectamente, rige en la relación entre el TPIP y la jurisdicción local. Las críticas determinaron que el Relator Especial propusiera una reformulación basada en el Art. $10^{\circ}$ del Estatuto de Yugoslavia y el Art. $42^{\circ}$ del "Proyecto de Estatuto de la CDI". ${ }^{80}$ Esta propuesta fue tenida en cuenta por el Proyecto de Código de 1996 (Art. 12º). El principio representa una indispensable protección para aquellas personas acusadas que ya han sido juzgadas por el TPIP; de esta manera no podrán ser juzgadas nuevamente por tribunales nacionales. Por otro lado no alcanza a personas que -por razones políticas- quedaron impunes ante sus tribunales nacionales $y$, efectivamente, merecen ser juzgadas. Las previsiones mencionadas resuelven el dilema garantizando una aplicación no restringida del principio ne bis in idem solamente en caso de una primera sentencia del TPIP; por otro lado, el TPIP puede proceder contra una persona juzgada por un tribunal nacional si ésta ha sido sentenciada sólo por delitos "comunes " en vez de delitos «internacionales» ${ }^{81}$ o si el juicio no fue imparcial o si la acusación no fue seriamente presentada. ${ }^{82}$ Adicionalmente, el Art. $12^{\circ}$ del Proyecto de Código de 1996 -teniendo en cuenta la propuesta de la CDI- autoriza

80 Ver $12^{\circ}$ Informe del Relator Especial, supra nota 60, Par. 89 y ss. (104). Para un enfoque crítico respecto del Art. $9^{\circ}$ ver Swart, en Bassiouni, supra nota 5, p. 173 y ss.

81 La distinción entre delitos «ordinarios" e «internacionales», no obstante, no se encuentra en discusión ya que el Art. $14^{\circ}$ Par. 7 ICCPR ya prohibe un segundo juicio si el acusado fue sentenciado "de acuerdo a la ley y el procedimiento penal de cada país»; por ejemplo: de acuerdo a la ley penal nacional (ordinaria) (veáse Crawford, 1994, supra nota 4, p. 149; Informe del Comité ad hoc, supra nota 7, Par. 179). Respecto al conflicto del Art. $10^{\circ}$ del Estatuto de Yugoslavia con la Constitución de Eslovenia ver P. Dolenc, «A Slovenian perspective on the statute and rules of the International Tribunal for the Former Yugoslavian, CLF vol. 5, No 2-3 (1994), pp. 451 a 469. En favor de la regulación, ver Nsereko, supra nota 2, pp. 514,515 .

82 Graefrath, supra nota 2, pp. 301, 302 y 310/311. Esta clase de casos pueden también presentarse en el ámbito nacional en cuanto a remisiones de castigo, en particular amnistías, indultos y perdones, sean demasiado generosas. El Art. $42^{\circ}$ Par. $2 \mathrm{~b}$ del Proyecto Alternativo, supra nota 10 , es por ello correcto al incluir estas medidas. 
otro juicio ante un tribunal nacional si el mismo hecho fue cometido dentro del territorio del Estado afectado o si el Estado fue la "víctima principal" del hecho (Art. 120 Par. 2 (b) ). Se deben tener en cuenta los períodos previos de encarcelamiento para evitar condenas excesivas (Art. 12० Par. 3). Esta previsión, de todas maneras, sólo se aplica al TPIP. ${ }^{83}$ Por ello, sigue sin aclararse si los tribunales nacionales al iniciar un segundo proceso de acuerdo al Art. $12^{\circ}$ Par. 2 (b) tendrán que tomar en consideración los períodos de encarcelamiento ya sufridos. La posición del acusado es -en relación a la incertidumbre que existe en este tema- extremadamente vulnerable.

Debe señalarse que todas estas reflexiones suponen la existencia de un TPIP. Ante la ausencia de un TPIP el rango del principio ne bis in idem es poco claro: son tantos los Estados que no lo reconocen que no puede sostenerse su validez universal. ${ }^{84}$ En casos en que sea posible una múltiple persecución, la protección suficiente de los imputados sólo puede ser lograda si los Estados afectados acuerdan en un nivel diplomático -con base en una investigación ya iniciada- dónde deberá desarrollarse el juicio y dónde deberá ser ejecutada la sentencia. ${ }^{85}$ Por ello, un Código Internacional debe contener un compromiso para efectuar consultas bilaterales a fin de evitar dobles juzgamientos; una detallada regulación del principio ne bis in idem debiera ser desarrollada y prevista en el Estatuto del TPIP.

Las cuestiones antes mencionadas se encuentran íntimamente relacionadas con el establecimiento de una jurisdicción nacional para crí-

83 El Art. 12० Par. 3 establece: «[...] el tribunal [...] tomará en cuenta la extensión de toda pena impuesta por un tribunal nacional [...] que ya ha sido cumplida"; "el tribunal" en este sentido quiere decir el TPIP, no una "corte nacional" (es igual al Art. $9^{\circ}$ Par. 5 del proyecto del Comité del Proyecto, también al UN-Doc. A/CN. 4/L.506 del 22/6/95, de distribución limitada). Los miembros del Comité del Proyecto son: Alexander Yankov (chairman), Doudou Thiam, Husain Al Baharna, James Crawford, Gudmundur Eiriksson, Qizi He, Peter Kabatsi, Mochtar Kusuma-Atmadja, Igor Ivanovich Lukashuk, Guillaume Pambou-Tchivounda, Robert Rosenstock, Alberto Szekely, F. Villagran-Kramer, Edmundo Vargas Carreno y Chusei Yamada.

84 El $12^{\circ}$ Informe del Relator Especial. Supra nota 60, parágrafos 97 y ss., en particular parágrafo 110 , rechazando la aplicación de este principio. Ver también el Informe de la CDI, supra nota 4, Par. 162 y Tribunal Constitucional alemán (BVerfGE 75/Iff.: sobre la validez del principio ne bis in idem en el Derecho Internacional Público). El Prof. H. Jung, no obstante, observa un incremento en la internacionalización del principio ( $Z u r$ "Internationalisierung des Grundsatzes ne bis in idem", en: Festschrift Schuiler Springorum, Köln, 1993, pp. 493 a 502, 500).

85 Ver Swart, en: Bassiouni, supra nota 5, p. 180. 
menes internacionales y cooperación internacional entre los Estados y, además entre un TPIP y los Estados. Mientras que el Proyecto de Código de 1991 omite esta cuestión el de 1996 contiene detalladas reglas al respecto. En principio, los Estados pueden perseguir a los sujetos que hayan cometidos crímenes internacionales -con la excepción de la agresión- en forma independiente de un TPIP (Art. $8^{\circ} \mathrm{del}$ Proyecto de Código del 1996). Si no los procesan deben extraditarlos a otro Estado que reclame su jurisdicción (Art. $9^{\circ}$, aut dedere aut judicare); no obstante, esto no cubre la transferencia o sumisión a un TPIP. ${ }^{86}$ El Código Internacional puede servir como base legal para la extradición (Art. 10 Par.2).

\subsection{Parte especial}

Como fue mencionada más arriba, el Proyecto de Código no trae una definición precisa de delito pero remite a los delitos regulados en la parte especial. La reducción sustancial de los delitos de doce a cinco (agresión, genocidio, delitos contra la humanidad, delitos contra la ONU y su personal y crímenes de guerra ${ }^{87}$ es la respuesta a amplias críticas, como señaló el Relator Especial:

« [...] el Relator Especial propone una lista más restringida [...] Ello es lo que la mayoría de los gobiernos desean. Para que un ilícito internacional se convierta en un delito comprendido en el código, no sólo debe ser extremadamente grave sino que la comunidad internacional debe decidir que se incluya. $"{ }^{88}$

86 CDI, supra nota 6, p. 51. Hay una clara distinción entre extradición (entre Estados) y transferencia o sometimiento (a un órgano internacional), ver por ejemplo el Art. $53^{\circ} \mathrm{del}$ Proyecto de Estatuto del TPIP y el Par. 3 de la Jugoslawien-Strafgerichtshof-Gesetz alemana (BGBI 1 1995, 485) y la motivación oficial (BTDrs. 13/57, S. 8, 10).

87 No obstante, el apartheid se encuentra incluido en el Par. (f) del Art. $18^{\circ}$ bajo al discriminación institucional como un delito contra la humanidad y el daño al medio ambiente en el Art. $20^{\circ}$ par. (g) como un crimen de guerra. En cuanto al terrorismo internacional ver nota 85 .

88 El 130 Informe del Relator Especial (en Parte II, Art. 15-26), UN-Doc.A/CN.4/466 del 24/3/95 (47a Sesión de 1995), Par. 4 (trad. del inglés). No obstante, el Relator Especial propuso incluir al terrorismo internacional y al tráfico ilícito de drogas. Varios miembros de la CDI rechazaron considerar "el tráfico ilícito de drogas" como un delito contra la paz y la seguridad de la humanidad (Informe de la $C D I$, supra nota 58, Par. 112 a 118, 135, 140); 
El criterio sustantivo para la reducción es que el delito, por un lado, sea reconocido por el Derecho Internacional consuetudinario y, por otro, que suponga una amenaza a la paz y a la seguridad internacional. Conforme al último criterio, dos de los delitos -agresión y genocidio- poseen por su naturaleza ese grado de amenaza para la comunidad internacional. Los tres restantes (delitos contra la humanidad, delitos contra las Naciones Unidas y su personal y crímenes de guerra) se encontrarían comprendidos sólo si reconocen el requisito adicional de haber sido cometidos en forma sistemática o a gran escala (cf. arts. $18^{\circ}$ al $20^{\circ}$ del Proyecto de Código de 1996). ${ }^{89}$

Para el primer criterio, el Derecho Internacional consuetudinario existente y los estatutos "oficiales" " se refieren a los siguientes cuatro grupos de crímenes internacionales: genocidio, agresión, crímenes de guerra y crímenes contra la humanidad. Uno puede subdividirlos en dos grupos. ${ }^{91}$ El primero referido a los delitos que se reflejan en el Derecho Internacional existente, con sólidas bases en los tratados internacionales y definiciones suficientemente claras para ser aplicados a casos concretos. Este grupo incluye al genocidio y a los crímenes de guerra. El segundo grupo se refiere a los delitos que hace tiempo existen en el Derecho Internacional pero carecen de bases convencionales y de definiciones uniformes. Este grupo incluye a la agresión y a los crímenes contra la humanidad.

las críticas más importantes concernientes a "terrorismo internacional" consistieron en que su definición no era lo suficientemente precisa (ibid., Par. 105-111, 138, 140). No obstante, el terrorismo internacional puede encontrarse comprendido por el Art. $18^{\circ}$ como un delito contra la humanidad cuando ese artículo refiere a su comisión por «cualquier grupo organizadom.

89 El requisito utilizado de manera sistemática implica una política preconcebida. El requisito a gran escala hace referencia a actos dirigidos contra una multiplicidad de víctimas tanto como el resultado de una serie de ataques o de un solo ataque masivo (CDI), supra nota 6, pp. 94 y ss).

90 Art. 1-5 del Estatuto de Yugoslavia y Art. 20 del Proyecto de la CDI (supra notas 2 y 4). Ver también el sumario del Relator Especial de la discusión de la CDI (Informe de la CDI, supra nota 58, Par. 130). En los delitos en particular ver Triffterer, supra nota 51, pp. 176 y ss.; Tomuschat, supra nota 5, pp. 278 y ss.; McCormack/Simposon, supra nota 5 . p. 13 y ss.

91 Para confrontar una visión diferente referida al Proyecto de Código en su totalidad, ver McCormack/Simpson, supra nota 5, pp. 13, 24, 42. El Relator Especial toma una aproximación similar (Informe de la CDI, supra nota 58, parágrafo 130-133). 
* El delito de genocidio (Art. 170 del Proyecto de Código de 1996) tiene una sólida base en los tratados ${ }^{92}$ y se encuentra universalmente reconocido constituyendo una norma de ius cogens. ${ }^{93}$ Hubo amplio consenso acerca de su inclusión en el código ${ }^{94}$ y bajo la jurisdicción de un TPIP.95 Todo ello implica que el genocidio es punible directamente en el marco del Derecho Penal internacional. ${ }^{96}$ Contra estos antecedentes existe una cuestión exclusivamente académica consistente en discutir si el genocidio constituye una categoría independiente o si cae bajo el catálogo de los delitos contra la humanidad. ${ }^{97}$

* Los crímenes de guerra incluyen, por un lado, las "violaciones graves» de la Convención de Ginebra y, por otro lado, (otras) «violaciones a las leyes y costumbres de la guerra». Las «violaciones graves» se encuentra en el Art. $50^{\circ}$ de la primera, Art. $51^{\circ}$ de la segunda, Art. $130^{\circ}$ de la tercera y Art. $147^{\circ}$ de la Cuarta Convención de Ginebra incluyendo, entre otros, el «homicidio doloso" y la "tortura o trato inhumano». ${ }^{98}$ Las "violaciones a las leyes de las costumbres de la guerra» constituyen una categoría de Derecho consuetudinario que incluye, por ejemplo, «el empleo de armas venenosas u otras armas calculadas para causar un sufrimiento innecesario» o la "desconsiderada destrucción de ciudades $[. .$.$] no justificadas por necesidades militares». { }^{99}$

92 La definición de genocidio corresponde al Art. $2^{\circ}$ de la "Convención sobre la prevención y el castigo del delito de genocidio". Esta Convención es considerada la expresión del derecho internacional en la materia (McCormack/Simpson, supra nota 5, p. 13, 14).

93 Meron, supra nota 72, p. 558.

94 Informe de la CDI, supra nota 58, Par. 78-83, 130, 132.

95 Informe del Comité ad hoc, supra nota 7, Par. 59.

96 Cf. Triffterer, supra nota 48, pp. 188 a 190. La criminalidad también proviene del hecho de que varios países convirtieron este delito en derecho nacional (interno) [ibid., p. Ej. 220 a) del Código Penal alemán (Strafgesetzbuch)].

97 Claramente, los delitos contra la humanidad se solapan en una considerable extensión bajo el genocidio; por ello, hay fuertes argumentos en favor de subsumir éste en aquellos (cf. Meron, supra nota 72, p. 558; Triffterer, supra nota 48, pp. 188-190).

98 Las cuatro Convenciones de Ginebra entraron en vigencia el 21 de octubre de 1950 y tenían 188 Estados partes al 31/3/1997, tres más que la ONU. Los dos protocolos adicionales entraron en vigencia el 7 de diciembre de 1978; al 31/3/1997 el $1^{\circ}$ vincula 147, el $2^{\circ} 139$ estados (ver internet: http://www.ICRC.Org/icrenews/2cde.htm).

99 Ver también los arts. $2^{\circ}$ y $3^{\circ}$ del Estatuto de Yugoslavia, supra nota 2, así como el $13^{\circ}$ Informe del relator Especial, supra nota 88, par. 110. Para un análisis crítico ver McCormack/ Simpson, Supra nota 5, pp. 36 a 39; Triffterer, supra nota 48, pp. 177 a 187 . Para el punto de vista de los Estados ver el Informe del Comité ad hoc, supra nota 7, parágrafo 72 a 76 . Para la discusión dentro de la CDI (ver su Informe, supra nota 58, parágrafos 98 a 103, 130, 132. 
Se encuentra altamente debatido si las leyes y las costumbres aplicables en conflictos armados deben incluir, también, aquellos conflictos armados no internacionales, destacándose el Art. $3^{\circ}$ de la Convención de Ginebra y el II Protocolo Adicional. ${ }^{100}$ El Tribunal de Yugoslavia, invocó la práctica de Estados ${ }^{101}$ que abarca desde la Guerra Civil española hasta los recientes conflictos de Somalia y Chechenia, argumentado en forma convincente que las leyes y las costumbres de la guerra en el sentido del Art. $3^{\circ}$ del Estatuto también alcanzan al conflicto armado interno. ${ }^{102}$ El Art. 20 Par. (f) del Proyecto de 1996 también incluye a los «actos cometidos en violación al Derecho humanitario internacional aplicable en conflictos armados de carácter no internacional" (sin resaltado en el original).

* Aparte de los ya mencionados problemas concernientes a la agresión, ${ }^{103}$ la determinación de qué debe entenderse por acto de agresión se encuentra altamente debatida. Más allá de que no se pueda distinguir claramente entre "guerra de agresión", «acto de agresión» o «amenaza de agresión", todos términos contenidos en los arts. $15^{\circ}$ y $16^{\circ}$ del Proyecto de Código de $1991 .{ }^{104}$ El Drafting Committee define la agresión como «uso de fuerzas armadas por un Estado contra la integridad territorial o la independencia política de otro Estado o de cual-

100 Ver especialmente Meron, supra nota 72, argumentando (p. 561), que «no existe justificación moral y una auténtica razón de persuasión, para tratar a los perpetradores de atrocidades en conflictos internos con mayor lenidad que aquellos involucrados en guerras internacionales». Ver también el Informe del Comité ad boc, supra nota 7, parágrafo 74.

101 El Tribunal, no obstante, entenderá como prácticas del Estado las "palabras" utilizadas (sus pronunciamientos oficiales, los manuales militares y las decisiones judiciales) más que "escritos", ello debido a que es sumamente difícil -sino imposible- señalar con precisión el comportamiento actual de las tropas en el campo. (Prosecutor vs. Dusko Tadic, supra nota 17. Рar. 99; ver también Meron, "The continuing role of custom in the formation of internatinal buamnitarian Laum, 90 AJIL (1996), pp. 238-249, p. 239). Escéptico acerca de esta tendencia contraria a la interpretación tradicional de las prácticas del Estado, ver B. Simma, "International buman rights law and general international law: a comparative analysis, en: Academy of European Law (ed.), Collected courses of the Academy of European Law, vol IV (1995), libro 2, pp. 153 a 236, 216 y ss.

102 Prosecutor vs. Dusko Tadic, supra nota 17, par. 86 y ss., Cf. Meron, supra nota 101, pp. 241-2; Greenwood, supra nota 74, pp. 279/280.

103 Ver supra notas 33, 75 y el texto correspondiente.

104 Cf. McCormack/Simpson, supra nota 5, p. 24 a 29; Triffterer, supra nota 52, pp. 202 a 207; Informe del Comité ad hoc, supra nota 7, parágrafos 63 a 71; para la discusión dentro de la CDI ver su Informe, supra nota 58, parágrafos 60 a 74, esp. 63, y 131, 132. 
quier otra manera contraria a la Carga de las Naciones", limitando así las extensas definiciones utilizadas en el Proyecto de Código de $1991 .^{105}$ El Art. 16º del Proyecto de Código de 1996 adopta la definición de agresión contenida en el Art. $6^{\circ}$ (a) del Estatuto del TMI sancionando a los líderes y organizadores que activamente participen u ordenen "la planificación, preparación, iniciación o apoyo de la agresión cometida por un Estado".

* Utilizando el título de violaciones sistemáticas o masivas a los derechos humanos el Art. 21 del Proyecto de Código del 1991 esencialmente extiende el concepto de delitos contra la humanidad, como se encuentran definidos en el Art. $6^{\circ}$ (c) del Estatuto del TMI, a todos los actos de esta naturaleza con independencia de las circunstancias en que han sido perpetrados. ${ }^{106}$ Por ello, el Relator Especial propone emplear las categorías mejor conocidas de crímenes contra la humanidad $^{107}$ y el Proyecto de Código de 1996 las adopta en su Art. 18 $8^{\circ}$. Por consiguiente, asesinato, exterminio, tortura, esclavización, persecución, discriminación institucionalizada, deportación, desaparición, ${ }^{108}$ violación y otras formas de abuso sexual y otros actos inhumanos se encuentran incluidos. ${ }^{109}$ Igualmente, los contenidos de esta categoría no se encuentran en discusión y la doctrina ha desarrollado varias definiciones. ${ }^{110} \mathrm{La}$ CDI en su comentario del Art. 20 $0^{\circ}$ del Proyecto de

105 Comité Proyectista, supra nota 83, Art. 15\%. No obstante, la versión final queda por ser vista. Para la definición original ver la Resolución de la AG 3314 (XXIX) del 14.12.1974 (Registros Oficiales, 29a. Sesión, suplemento No 19, A/9619 y Corr. 1).

106 Cf. McCormack/Simpson, supra nota 5, p. 14, 15. Ver también Prosecutor vs. Dusko Tadic, supra nota 17, Par. 141: «establece la regla [...] que los delitos contra la humanidad [...] no requieren (tener) relación” a ningún conflicto en absoluto. Cf Meron, supra nota 101, p. 242; Greenwood, supra nota 74, p. 282.

107 13er Informe del Relator Especial, supra nota 88, 64-97; ver también Informe de la CDI, supra nota 58, parágrafos 87 a 97, 130, 133.

108 Ver el UNGA-Declaration on the Protection of all Persons from Enforced Disappearances (Res. 47/133 del 18/12/1992) y la Convención Interamericana sobre la Desaparición Forzada de personas del 9/6/1994 (OEA/Ser.P, AG/doc.3114/94 rev.1 del 8/6/1994).

109 Cf. Art. $5^{\circ}$ del Estatuto de Yugoslavia, supra nota 3, y Art. $3^{\circ}$ del Estatuto de Ruanda, supra nota 3.

110 Jescheck, por ejemplo, clasifica los delitos contra la humanidad con un subgrupo de los delitos contra el derecho internacional los que, de acuerdo con esta definición, representan delitos internacionales (EPIL, Instalment 8, 1985, p. 332). Bassiouni también los considera como «una categoría de delitos internacionales» refiriendo al Art. $6^{\circ} \mathrm{c}$ del Estatuto del TM1; al mismo tiempo critica el concepto por ser de una "estructura legal caótica con muchas cuestiones legales sin resolver" (Crimes against Humanity in International Criminal Law, 
Estatuto realiza la siguiente definición: «[...] la definición de delitos contra la humanidad comprende actos inhumanos de diversa entidad incluyendo las violaciones masivas y sistemáticas perpetradas respecto de una parte o de toda una población civil. Lo que marca el contraste de esa clase de delitos reside en su naturaleza sistemática y a gran escala. Las formas particulares de actos ilegítimos [...] son menos cruciales para la definición que los factores de magnitud y política deliberada así como que se hayan perpetrado contra la población civil en todo o en parte [...] El concepto "dirigidos contra cualquier población civil", debe ser tomado como referido a hechos cometidos como parte de un ataque amplio y sistemático contra una población civil por motivos nacionales, políiticos, étnicos, raciales o religiosos. Los actos particulares a los que se refiere la definición son actos deliberadamente cometidos como parte de esa clase de ataquem. ${ }^{111}$

Esta definición -de acuerdo con el Art. $18^{\circ}$ del Proyecto de Código del 1996- es lo suficientemente clara y ciertamente constituye un paso adelante. No obstante, dentro del entramado del reciente debate en el Comité ad hoc de la ONU se advirtió nuevamente que «ninguna convención contiene un reconocimiento general y una definición jurídica lo suficientemente precisa de delitos contra la humanidadm. ${ }^{112}$ Ello muestra claramente que todavía se requiere una definición más precisa.

Sin perjuicio de los problemas pendientes, se puede identificar un extendido consenso acerca de la inclusión de estos delitos en un Código Penal Internacional y la jurisdicción (respectiva) de un TPIP. ${ }^{113}$ La inclusión del nuevo Art. $19^{\circ}$ (delitos contra la ONU y su personal) se presenta como la más sorprendente. La misma es consecuencia del

Dordrecht 1992, pp. 47, 470, 480, 481). De acuerdo a Ferencz, los delitos contra la humanidad no representan «incidentes aislados sino, acciones de envergadura y sistemáticos, generalmente llevadios a cabo por autoridades oficiales que, por la dimensión de su brutalidad, convocan a la comunidad internacional al agredir y ver peligrar la conciencia humanitaria" (EPIL, Instalment 1, 1992, pp. 869, 870). Ver también Triffterer, supra nota 51, ps. 187 a 202; McCormack/Simpson, supra nota 5, pp. 14 a 24.

111 Sin resultado en el original (Informe de la CDI, supra nota 4, par. 91, p. 76; trad. del inglés).

112 Informe del Comité ad hoc, supra nota 7, parágrafo 78 (trad. del inglés). Cfr. también Informe de la CDI, supra nota 58, parágrafo 88.

113 Informe del Comité ad hoc, supra nota 7, parágrafos 59,63,72,77; Informe de la CDI, supra nota 58, par. 130, 140. 
incremento de ataques contra el personal de la ONU que condujo a la Asamblea General a adoptar la correspondiente Convención ${ }^{114}$ y al Secretario General a demandar protección adecuada para su personal. ${ }^{15}$ La previsión es ciertamente un signo político; uno se pregunta, no obstante, si efectivamente es realmente necesario dotar de un trato privilegiado al personal de la ONU cuando los ataques en cuestión ya se encuentran incluídos en otros delitos y el personal de la ONU se encuentra en las zonas de conflicto armado en la misma posición que el resto de la población civil.

\section{Perspectivas futuras}

De momento, el futuro del Estatuto para la constitución de un TPIP y el establecimiento de un Código Penal Internacional es difícil de predecir. La Comisión Preparatoria fue, como inicialmente se señaló, establecida con el propósito de combinar «discusiones posteriores en la elaboración de los textos, con miras a preparar un texto consolidado para la constitución de un TPIP como un nuevo paso tendente a ser considerado por una conferencia plenipotenciaria». ${ }^{116} \mathrm{Su}$ primer proyecto se ocupó de "los principios generales de la ley penal» ${ }^{117}$ combinado con el -ciertamente mejorado- Proyecto de Código de 1996, y trató tanto de incorporarlo en un Estatuto como de separar claramente las normas sustantivas de las procesales. En cualquier caso, la ley penal sustantiva requiere un mayor desarrollo que -a pesar de que es un esfuerzo difícil de llevar adelante el de redactar una parte general que convenza tanto a los juristas del Common Law como a los del Derecho continental- no será imposible. ${ }^{118}$ Tomándolo como se encuentra, el Proyecto de Código de 1996 puede ser adoptado bajo la forma de una Convención por la $A G$ o por una conferencia de Estados, en la forma de una declaración de la AG o, como ya se mencio-

114 Resolución de la AG 49/59, del 9/12/1994.

115 Informe de la CDI, supra nota 6, pp. 104 y ss.

116 Informe del Comité ad hoc, supra nota 7, parágrafo 257 (trad. del inglés).

117 Supra nota 8.

118 Desde una óptica escéptica, ver también Tomuschat, supra nota 5, p. 291; McCormack/ Simpson, supra nota 5, p.46; ver, por otro lado, el punto de vista aparentemente optimista de Crawford, 1995, supra nota 4, p.415. 
nó, incorporándola en el Estatuto. Aunque no exista un acuerdo formal en los aspectos de tiempo, una conferencia de Estados probablemente se llevará a cabo en 1998 luego de las tres reuniones de la Comisión Preparatoria en 1997. ${ }^{119}$

En todo caso una parte general relativamente sólida requerirá un análisis detenido de la jurisprudencia y los esfuerzos de codificación desarrollados desde Nuremberg, y que deberá apoyarse en un estudio legal comparativo para establecer los elementos estructurales fundamentales del Derecho Internacional Penal sustantivo moderno. Una investigación de esa clase llevará tiempo y es posible que sea un error político esperar a sus conclusiones.

Finalmente, a pesar de la euforia que rodea ciertos desarrollos políticos positivos, no debe perderse de vista que la internacionalización del Derecho Penal, en particular la creación de mecanismos de justicia penal internacional, sólo alcanzarán sus expectativas si las competencias respectivas e, incluso, si las obligaciones de perseguir ciertos actos definidos como "crímenes internacionales", son internalizadas; por ejemplo, reconocidas y aceptadas por los fiscales, los acusados y las víctimas como materialmente válidas y legalmente justas. ${ }^{120}$ Los particulares, como opuestos al Estado, no pueden iniciar procedimientos ante un TPIP. ${ }^{121}$ Por Ello, el mantenimiento y mejoramiento de los mecanismos de protección existentes, como los procedimientos de quejas individuales basados en las convenciones internacionales de derechos humanos (protocolos adicionales), remedios del derecho civil ${ }^{122}$ y cooperación interestatal en materia penal, ${ }^{123}$ pueden servir en

119 Informe del Comité ad hoc, supra nota 7, par.252; Informe de la PrepCom, supra nota 9, parágrafos 368,370 .

120 Respecto de la discrepancia entre «internacionalización" e «internalización» en el contexto exclusivo de los derechos humanos ver Simma, supra nota 101, p. 191.

121 En este sentido, la cruel ironía de la protección internacional de los derechos humanos, como fue señalado por Reisman/Koven Levit es mantenida sin perjuicio del reconocimiento de responsabilidades individuales "Reflections on the problem of individual responsability for violations of human rights", en: Cançado Trindade (ed.), The modern world of human rights. Essays in honor of Thomas Buergenthal, San José (IIDH) 1996, pp. 419 a 436, p. 421).

122 Ver S. Walther, "Private» Ahndung schwerer Menschenrechtsverletzungen: Grenzüberschreitende DenkanstöBe zum internationalen Strafrecht), en: Arnold/Burkhardt/Gropp/ Koch (eds.), Grenzuiberschreitungen, Beiträge zum 60. Geburtstag von Albin Eser, Freiburg 1995, pp. 229 a 247.

123 En cualquier caso, el principio de complementariedad implica la delincuencia inter- 
ciertos casos a la causa de los derechos humanos mucho más que lo que ofrecen «soluciones empaquetadas» del Derecho Penal Internacional; soluciones que, con demasiada frecuencia, tienden a fallar debido a la ausencia de voluntad política por parte de la comunidad de Estados para hacerlas operativas. 
Cuadro comparativo de las disposiciones más importantes de los estatutos proyectados para el establecimiento de un Tribunal Penal Internacional Permanente (TPIP)

\begin{tabular}{|c|c|c|c|}
\hline & $\begin{array}{l}\text { Resoluciones del Consejo de Seguridad de la } \\
\text { ONU (1993/94)1 }\end{array}$ & Proyecto de la CDI (1994) & Proyecto altenativo (1995) \\
\hline $\begin{array}{l}\text { Naturaleza } \\
\text { jurídica/estructura }\end{array}$ & $\begin{array}{l}\text { Establecimiento como organo subsidiario (Art. } \\
29^{\circ} \text { Carta de las NU) con base en el Cap. VI } \\
\text { de la Carta de la ONU. Dos tribunales de } \\
\text { juicio (1 } 1^{\text {a }} \text { instancia) y cámara de apelación con } \\
\text { dos salas, fiscal, registro (arts. } 11^{\circ} \text { al } 17^{\circ} \text { ). }\end{array}$ & $\begin{array}{l}\text { Tratado: TPI permanentel ... Presidencia, } \\
\text { juicio y cámata de apelación, fiscal, registro } \\
\left.\text { (arts. } 1^{\circ} \text { al } 19^{\circ}, 22^{\circ}\right) \text {. }\end{array}$ & Como en el Proyecto de la CDI \\
\hline Jurisdicción & & 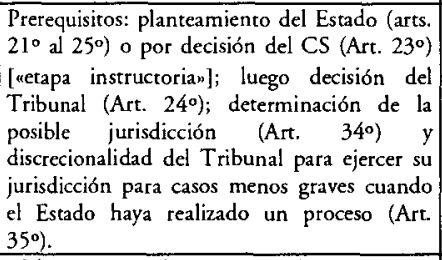 & $\begin{array}{l}\text { En principio como en el Proy. de la CDI, pero se le reconoce } \\
\text { al Estado la posibilidad de cuestionar y el papel del CS se } \\
\text { encuentra en discusión (Part. III). }\end{array}$ \\
\hline $\begin{array}{l}\text {-Materia sujeta } \\
\text { jurisdicción }\end{array}$ & $\begin{array}{l}\text { graves violaciones de las Convenciones de } \\
\text { Ginebra, } 2 \text { violaciones de las leyes o a las } \\
\text { costumbres de la guerra, genocidio, crímenes } \\
\text { contra la humanidad; sin enumeración taxativa } \\
\text { (arts. } 1^{\circ} \text { al } 5^{\circ} \text { ) }\end{array}$ & $\begin{array}{l}\text { "delitos" específicos (genocidio, agresión, } \\
\text { violaciones a las leyes de la guerra, crimenes } \\
\text { contra la humanidad) y delitos previstos en } \\
\text { tratados "con relevancia internacional" (Art. } \\
20^{\circ} \text { ); } 3 \text { jurisdicción ipso iure en materia de } \\
\text { genocidio. }\end{array}$ & $\begin{array}{l}\text { En principio como en el Proyecto de la CDI, pero con una } \\
\text { exacta determinación de los delitos y con un anexo relativo a } \\
\text { otros delitos que pueden ser adicionados. }\end{array}$ \\
\hline -Jurisdicción personal & $\begin{array}{l}\text { personas físicas que hayan "planeado, instigado, } \\
\text { ordenado, cometido o de cualquier otra manera } \\
\text { ayudado [...] en la planificación, preparación o } \\
\text { ejecución" de los delitos mencionados; } \\
\text { exclusión del "acto del estado" y la doctrina de } \\
\text { la uorden del superior" (arts. } 6^{\circ} \text { al } 7^{\circ} \text { ). }\end{array}$ & Toda persona física (ex Art. $21^{\circ}$ parágrafo 1 ) & Como en el Proyecto de la CDI \\
\hline
\end{tabular}

' Los estaturos aprobados por las dos resoluciones se refieren a la antigua Yugoslavia y Ruanda y son prácticamente idénticos; por lo tanto, una discusión separada solo es necesaria en aquellas pequeñas áreas donde las resoluciones difieren. El análisis se basa en la resolución 827 de Yugoslavia (las «reglas sobre procedimiento y prueba" no son renidas en consideración).

${ }^{2}$ La resolución 827 se refiere a las "graves violaciones" de las Convenciones de Ginebra y a las leyes y costumbres de la guerra, mientras que la resolución 955 se refiera al artículo común $3^{\circ}$ de las Convenciones de Ginebra y al segundo protocolo adicional, ya que el conflicto de Ruanda es considerado como "no-internacional".

3 "Ver los tratados en los anexos, en particular las Convenciones de Ginebra, sobre tortura (1984) y sobre narcotráfico (1988). 


\begin{tabular}{|c|c|c|c|}
\hline & $\begin{array}{l}\text { Resoluciones del Consejo de Seguridad de la } \\
\text { ONU (1993/94)1 }\end{array}$ & Proyecto de la CDI (1994) & Proyecto altenativo (1995) \\
\hline $\begin{array}{l}\text {-Jurisdicción } \\
\text { territorialtemporal }\end{array}$ & $\begin{array}{l}\text { Territorio de la antigua Yugoslavia/del } 1 / 1 / 91 \\
\text { hasta el restablecimiento de la paz y la } \\
\text { seguridad2. }\end{array}$ & $\begin{array}{l}\text { Ilimitada en principio, sujeta a la aceptación } \\
\left.\text { de la jurisdicción por el Estado (Art. } 22^{\circ}\right) \text {. }\end{array}$ & Como en el Proyecro de la CDI \\
\hline -furisdicción nacional? & $\begin{array}{l}\text { En principio, jurisdicción concurrente, pero } \\
\text { con primacia del TPIP en caso de conflicto de } \\
\text { competencia (Art. } 9^{\circ} \text { ). }\end{array}$ & $\begin{array}{l}\text { Primacía del TPIP en los supuestos de la } \\
\text { materia sujeta a su jurisdicción (Ex. } 51 \text { y ss), } \\
\text { si no complementario (Art. 35\%, ver más } \\
\text { arriba y el preámbulo). }\end{array}$ & Como el Proyecto de la CDI \\
\hline \multicolumn{4}{|l|}{ Procedimiento } \\
\hline -Etapa instructoria & $\begin{array}{l}\text { Investigación y acusación a cargo de un fiscal, } \\
\text { revisión y posibles medidas de coerción por un } \\
\text { juez de la cámara de apelación (arts. } 18^{\circ} \text { y } 19^{\circ} \text { ). }\end{array}$ & $\begin{array}{l}\text { Investigación y acusación a cargo del fiscal, } \\
\text { revisión y posibles medidas de coerción por la } \\
\text { "Presidencia" (arts. } 25^{\circ} \text { al } 31^{\circ} \text { ). }\end{array}$ & $\begin{array}{l}\text { En principio como el Proyecto de la CDI, sólo pequeños } \\
\text { cambios (ver más adelante). }\end{array}$ \\
\hline - Investigación & $\begin{array}{l}\text { Ex officio o con base en información }[\ldots] \text { de } \\
\text { cualquier ufuente». }\end{array}$ & $\begin{array}{l}\text { Con base en la denuncia formulada por un } \\
\text { Estado parte de la Convención sobre } \\
\text { Genocidio o -en el supuesto de otros delitos- } \\
\text { haber aceptado la jurisdicción del Tribunal; o } \\
\text { con base en una decisión del CS (Art. 25० } \\
\text { parágrafo } 4 \text { en relación al Art. } 23^{\circ} \text { ) }\end{array}$ & Como el Proyecto de la CDI. \\
\hline - Acusación & $\begin{array}{l}\text { Sobre un caso prima facie, confirmación o } \\
\text { rechazo del juez. }\end{array}$ & $\begin{array}{l}\text { Con base en un caso prima facie; La } \\
\text { "Presidencia" confirma, modifica o rechaza la } \\
\text { acusación (ex 27 Par. 2); también revisa las } \\
\text { decisiones negativas del fiscal (no acusar) } \\
\text { cuando un estado lo reclama o el CS y puede } \\
\text { requerir al fiscal que reconsidere su decisión. } \\
\text { Se tiene en consideración el proceso nacional } \\
\text { y la gravedad del deliro (Art. } 35^{\circ} \text { ). }\end{array}$ & $\begin{array}{l}\text { En principio como el Proyecto de la CDI, pero la definición } \\
\text { de caso prima facie en el sentido de una fuerte sospecha de un } \\
\text { acto criminal y el derecho a que las partes sean oídas ( } 27 \text { Par. } \\
1,2 \text {. }\end{array}$ \\
\hline - Medidas coetcitivas? & $\begin{array}{l}\text { Sólo si es ordenada por el juez (p. ej. prisión } \\
\text { preventiva); el fiscal sólo puede requerit las } \\
\text { medidas de coerción y adoptar algunas medidas } \\
\text { de investigación (p.ej. recibir declaración } \\
\text { indagatoria). }\end{array}$ & $\begin{array}{l}\text { Similar a las resoluciones del CS de la ONU, } \\
\text { con previsiones más precisas, particularmente } \\
\text { en cuanto a las condiciones de detención } \\
\left(\text { Art. } 28^{\circ}\right) \text {. }\end{array}$ & Como en el Proyecto de la CDI. \\
\hline
\end{tabular}

' Los estatutos aprobados por las dos resoluciones se refieren a la antigua Yugoslavia y Ruanda y son prácticamente idénticos; por lo tanto, una discusión separada solo es necesaria en aquellas pequeñas áreas donde las resoluciones difieren. El análisis se basa en la resolución 827 de Yugoslavia (las "reglas sobre procedimiento y prueban no son tenidas en consideración).

: La resolución 955 también se refiere a los territorios de los Estados vecinos respecto de los crímenes de ciudadanos ruandeses y es válida desde el 1/1 al $31 / 12 / 1994$. 


\begin{tabular}{|c|c|c|c|}
\hline & $\begin{array}{l}\text { Resoluciones del Consejo de Seguridad de la } \\
\text { ONU (1993/94) }\end{array}$ & Proyecto de la CDI (1994) & Proyecto altenativo (1995) \\
\hline Procedimiento en el juicio & arts. $20^{\circ}$ y $21^{\circ}$ & arts. $32^{\circ}$ al $47^{\circ}$ & arts. $32^{\circ}$ al $47^{\circ}$ \\
\hline - Ley aplicable & $?$ & $\begin{array}{|lcr|}\text { Estatutos, tratados aplicables y reglas y } \\
\text { principios generales del } & \text { Derecho } \\
\text { Internacional con uaplicación extensivat en la } \\
\text { ley nacional (Art. 330) }\end{array}$ & $\begin{array}{l}\text { Como en el Proyecto de la CDI pero presta mayor atención a } \\
\text { los elementos que deben ser regulados en una "Parte General". }\end{array}$ \\
\hline - Trámite & $\begin{array}{l}\text { Lectura de la acusación, declaración del } \\
\text { acusado, comparescencia, fecha del juicio. }\end{array}$ & $\begin{array}{l}\text { Lecrura de la acusación, aseguramiento de los } \\
\text { derechos del acusado, su declaración (Art. } \\
38^{\circ} \text { ). }\end{array}$ & Como en el Proyecro de la CDI. \\
\hline - Pruebas & $?$ & $\begin{array}{l}\text { Declaraciones de los testigos de acuerdo a la } \\
\text { ley nacional, incluyendo previsiones en } \\
\text { materia de falso testimonio; el TPIP decide } \\
\text { acerca de la admisibilidad y relevancia de las } \\
\text { pruebas, no requiere pruebas de público y } \\
\text { notorio; no es admisible la prueba obtenida } \\
\text { ilegalmente (Art. 44\%); es admisible en el } \\
\text { juicio posterior la prueba grabada con } \\
\text { asistencia de la cámara de acusación (Art. } \\
\text { 37\%). }\end{array}$ & $\begin{array}{l}\text { Sus propias reglas en materia de pruebas; grabaciones de audio } \\
\text { o video como prueba documental; se encuentra prohibido el } \\
\text { uso de pruebas obtenidas mediante "serias violaciones" a los } \\
\text { derechos humanos; derecho de los testigos a no testificar; } \\
\text { sanciones posibles contra los testigos (44); "prueba grabada" } \\
\text { sólo en caso de asistencia letrada (37). }\end{array}$ \\
\hline - Juicio & $\begin{array}{l}\text { Mayoría simple, deliberación en público, } \\
\text { acompañada de fundamentación por escrito } \\
(\text { Art. 230). }\end{array}$ & $\begin{array}{l}\text { Respecto de la culpabilidad y la sentencia; } \\
\text { mayoría simple, la imposibilidad de llegar a } \\
\text { un acuerdo determina un nuevo juicio; } \\
\text { deliberaciones secretas, sentencia por escrito y } \\
\text { deliberación en la sala de audiencias (Art. } \\
45^{\circ} \text { ). }\end{array}$ & Como en el Proyecto de la CDI. \\
\hline - Sentencia & $\begin{array}{l}\text { Sólo encarcelamiento; duración de acuerdo a la } \\
\text { "práctica general" en la antigua Yugoslavia y a } \\
\text { la gravedad del delito y a las circunstancias } \\
\text { personales del autor; adicionalmente, orden de } \\
\text { devolución de propiedades o efectos obrenidos } \\
\text { con motivo de la conducta criminal (Art. } 24^{\circ} \text { ) }\end{array}$ & $\begin{array}{l}\text { Encarcelamiento o multa, duración y cuantía } \\
\text { de acuerdo a la ley nacional del condenado, el } \\
\text { lugar de comisión del hecho y el Estado } \\
\text { competente (Art. } 47^{\circ} \text { ); censura del proceso; } \\
\text { consideración de la gravedad del delito y las } \\
\text { circunstancias personales del autor (Art. } 46^{\circ} \text { ). }\end{array}$ & $\begin{array}{l}\text { En principio como en el Proyecto de la CDI, pero con una } \\
\text { pena mínima de un año de encarcelamiento y multa adicional } \\
\text { (no como pena única); confiscación de los objetos y elementos } \\
\text { provenientes del delito; cómputo del tiempo de detención en } \\
\text { prisión preventiva (47). }\end{array}$ \\
\hline Remedios Judiciales & $\begin{array}{l}\text { Motivos para la apelación y la revisión (arts. } \\
25^{\circ} \text { y } 26^{\circ} \text { ). }\end{array}$ & $\begin{array}{l}\text { Motivos y consecuencias para la apelación y } \\
\text { la revisión (arts. } 48^{\circ} \text { al } 50^{\circ} \text { ). }\end{array}$ & arts. $48^{\circ}$ al $50^{\circ}$. \\
\hline - Apelación & $\begin{array}{l}\text { En caso de una incorrecta interpretación del } \\
\text { Derecho o de los hechos. }\end{array}$ & $\begin{array}{l}\text { En caso de un juicio injusto (imfair trial), } \\
\text { error en la interpretación del Derecho o los } \\
\text { hechos: nueva decisión o juicio; en caso de } \\
\text { que no exista proporcionalidad entre el delito } \\
\text { y la sentencia: corrección de la sentencia (Art. } \\
48^{\circ}, 49^{\circ} \text { ). }\end{array}$ & $\begin{array}{l}\text { En principio como en el Proyecto, de la CDI pero: error de } \\
\text { hecho solo en caso de que el motivo de la apelación sea la } \\
\text { earbitrariedad (miscarriage of justice); el fiscal y el acusado } \\
\text { tienen el derecho a recurrir (48). }\end{array}$ \\
\hline
\end{tabular}




\begin{tabular}{|c|c|c|c|}
\hline - Revisión & $\begin{array}{l}\text { En caso de nuevas pruebas sobre los hechos que } \\
\text { tengan entidad suficiente. }\end{array}$ & $\begin{array}{l}\text { Similar a las Resoluciones del CS de las NU: } \\
\text { la Presidencia puede requerir una decisión o } \\
\text { un nuevo juicio por una cámara o trasladar la } \\
\text { cuestión a la cámara de apelación (Arr. } 50^{\circ} \text { ). }\end{array}$ & Como en el Proyecto de la CDI. \\
\hline- Otros & & $\begin{array}{l}\text { Hábeas corpus durante la instrucción (Art. } \\
290 \text { Par. 3). }\end{array}$ & $\begin{array}{l}\text { Como en el Proyecto de la CDI y un derecho adicional a } \\
\text { recurrir las medidas adopladas en la etapa de instrucción ( } 48 \\
\text { Par. 1). }\end{array}$ \\
\hline \begin{tabular}{|l|} 
Ejecución de la sentencia \\
\end{tabular} & arts. $27^{\circ}$ y $28^{\circ}$ & $\begin{array}{l}\text { Prerequisito: reconocimiento del proceso por } \\
\text { los Estados partes (Art. } 58^{\circ} \text { ). }\end{array}$ & $\begin{array}{l}\text { En principio como en el Proyecto de la CDI pero reforzando } \\
\text { la obligación legal con la expresión «atenerse* (abide). }\end{array}$ \\
\hline - Regla general & $\begin{array}{l}\text { En un Estado de acuerdo a su ley y bajo la } \\
\text { supervisión del TPIP }\end{array}$ & $\begin{array}{l}\text { Similar a las resoluciones de la ONU si es } \\
\text { imposible en el «Estado huésped» (Art. 59\%). }\end{array}$ & $\begin{array}{l}\text { Adicional a la CDI: aceptación formal del Estado; que no haya } \\
\text { consentimiento del sentenciado; también aplicable a las multas } \\
\text { y a las medidas de confiscación (59). }\end{array}$ \\
\hline - Excepciones & $\begin{array}{l}\text { Perdón o conmutación de la condena se } \\
\text { encuentran sometidas al control del TPIP. }\end{array}$ & $\begin{array}{l}\text { Perdón, excarcelación juratoria (parale) y } \\
\text { conmuración de sentencias de acuerdo a la ley } \\
\text { nacional con base en el requerimiento de un } \\
\text { condenado por el TPIP (Art, } 60^{\circ} \text { ). }\end{array}$ & $\begin{array}{l}\text { Sin remisiones de acuerdo a la ley nacional: la decisión sólo le } \\
\text { corresponde al TPIP (60). }\end{array}$ \\
\hline Derechos y garantías & 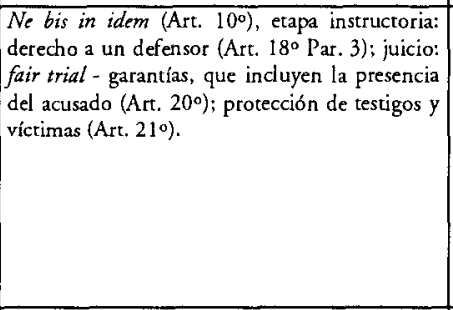 & 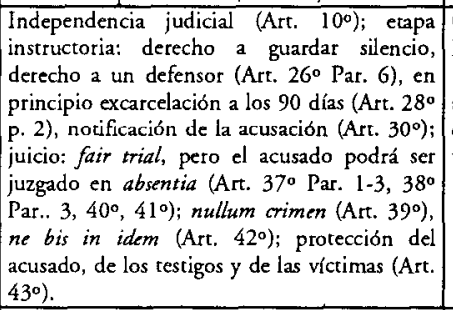 & $\begin{array}{l}\text { Como en el Proyecto de la CDI con enmiendas en Art. } 26^{\circ} \\
\text { Par. } 6,377^{\circ} \text { (d juicio in absentia tiene mayores requisitos), } 41^{\circ} \\
\text { (derecho a controlar las pruebas por la defensa), } 42^{\circ} \text { (no es } \\
\text { aplicable en caso de exclusión de la punibilidad; teniendo en } \\
\text { consideracion otras sanciones), } 43^{\circ} \text { (servicio para testigos y } \\
\text { victimas). }\end{array}$ \\
\hline Otras disposiciones & Cooperación judicial y asistencia (Art. 29०) & $\begin{array}{l}\text { Cooperación judicial y asistencia (arts. } 51^{\circ} \\
57^{\circ} \text { ), especialmente el Tribunal puede } \\
\text { requerir al estado medidas provisionales (Art. } \\
52^{\circ} \text { ). }\end{array}$ & Algunos cambios (arts. $51^{\circ}$ al $57^{\circ}$ ). \\
\hline
\end{tabular}

